\title{
CD44 in Ovarian Cancer Progression and Therapy Resistance-A Critical Role for STAT3
}

\author{
Antons Martincuks ${ }^{1+}$, Pei-Chuan $\mathrm{Li}^{1+}$, Qianqian Zhao ${ }^{1}$, Chunyan Zhang ${ }^{1}, \mathrm{Yi}-\mathrm{Jia} \mathrm{Li}^{1}$, \\ Hua $\mathrm{Yu}^{1 *}$ and Lorna Rodriguez-Rodriguez ${ }^{2 *}$ \\ 1 Department of Immuno-Oncology, Beckman Research Institute, City of Hope Comprehensive Cancer Center, Duarte, \\ CA, United States, 2 Department of Surgery, City of Hope Comprehensive Cancer Center, Duarte, CA, United States
}

OPEN ACCESS

Edited by:

Gennaro llardi,

Federico II University Hospital, Italy

Reviewed by:

Anup Kumar Singh,

Beckman Research Institute, City of

Hope, United States

Fuming $L i$,

University of Pennsylvania,

United States

*Correspondence:

Hua Yu

hyu@coh.org

Lorna Rodriguez-Rodriguez

lorrodriguez@coh.org

${ }^{\dagger}$ These authors have contributed equally to this work

Specialty section:

This article was submitted to Molecular and Cellular Oncology,

a section of the journal

Frontiers in Oncology

Received: 31 July 2020

Accepted: 22 October 2020

Published: 01 December 2020

Citation:

Martincuks A, Li P-C, Zhao Q, Zhang C, Li Y Y-J, Yu H and

Rodriguez-Rodriguez L (2020)

CD44 in Ovarian Cancer Progression

and Therapy Resistance-

A Critical Role for STAT3.

Front. Oncol. 10:589601.

doi: 10.3389/fonc.2020.589601
Despite significant progress in cancer therapy over the last decades, ovarian cancer remains the most lethal gynecologic malignancy worldwide with the five-year overall survival rate less than 30\% due to frequent disease recurrence and chemoresistance. CD44 is a non-kinase transmembrane receptor that has been linked to cancer metastatic progression, cancer stem cell maintenance, and chemoresistance development via multiple mechanisms across many cancers, including ovarian, and represents a promising therapeutic target for ovarian cancer treatment. Moreover, CD44-mediated signaling interacts with other well-known pro-tumorigenic pathways and oncogenes during cancer development, such as signal transducer and activator of transcription 3 (STAT3). Given that both CD44 and STAT3 are strongly implicated in the metastatic progression and chemoresistance of ovarian tumors, this review summarizes currently available evidence about functional crosstalk between CD44 and STAT3 in human malignancies with an emphasis on ovarian cancer. In addition to the role of tumor cell-intrinsic CD44 and STAT3 interaction in driving cancer progression and metastasis, we discuss how CD44 and STAT3 support the pro-tumorigenic tumor microenvironment and promote tumor angiogenesis, immunosuppression, and cancer metabolic reprogramming in favor of cancer progression. Finally, we review the current state of therapeutic CD44 targeting and propose superior treatment possibilities for ovarian cancer.

Keywords: CD44, STAT3, chemoresistance, tumor microenvironment, ovarian cancer, tumor progression, angiogenesis, immunosuppression

\section{INTRODUCTION}

Ovarian cancer is a global problem and is the most common cause of death in female patients with gynecological tumors in the USA, ranking number five in female cancer deaths (1). The etiology of ovarian cancer remains elusive and the main reason for high mortality rates is the lack of effective screening strategies that results in disease diagnosis at an advanced stage (2). Standard of care for newly diagnosed ovarian cancer patients typically consists of debulking surgery and platinum-based chemotherapy. However, despite current treatment progress in recent years, the prognosis remains 
poor with five-year survival rates of $<30 \%$ depending on geographical location $(3,4)$. Advanced disease has a recurrence rate of $>80 \%$ and demonstrates significant heterogeneity of tumor cells and underlying molecular mechanisms. This leads to resistance to standard chemotherapy regimens (5-9). Given the poor prognosis, limited early screening options, and high prevalence of ovarian cancer chemoresistance, it is vital to identify predictive molecular markers of survival and therapy resistance and identify novel therapeutic targets. CD44, a cell surface protein, has been previously shown to play an important role in cancer stem cell (CSC) function and driving the progression of several tumor types, including ovarian (10-12). There is ample evidence for CD44 expression and signaling in the development of cancer therapy resistance and several publications in various tumor models demonstrate functional crosstalk between CD44 and STAT3 (signal transducer and activator of transcription 3). Here, we explore CD44 function in the context of promoting ovarian cancer therapy resistance, review relevant literature evidence linking CD44 and STAT3 cooperation in tumor progression, and discuss different therapeutic strategies to target CD44 alone or in combination with other molecular targets to improve clinical outcomes in ovarian cancer patients.

\section{CD44 STRUCTURE AND FUNCTION}

CD44 (also referred to as HCAM, Hermes antigen or lymphocyte homing receptor) is a cell surface glycoprotein that mediates cellular responses to the microenvironment and is involved in a variety of intracellular processes including proliferation, cell survival, motility, and differentiation (13). CD44 was first identified and cloned in $1989(14-16)$ and represents a polymorphic group of surface proteins that range from 80 to $200 \mathrm{kDa}$ in size $(12,17,18)$. All CD44 proteins are encoded by a single highly conserved gene that is comprised of 20 exons in mouse and 19 exons in human genome. The size heterogeneity of CD44 gene products is explained by either different posttranslational modifications ( $\mathrm{N}$ - and $\mathrm{O}$-glycosylation) or by alternative splicing, which gives rise to many CD44 isoforms (19-21). The first and last five exons are always expressed and encode the smallest standard isoform (CD44s) with the central ten variable exons spliced out (Figure 1A). The variable middle nine exons can be alternatively spliced and assembled in different combinations, referred to as CD44 variant (CD44v) isoforms. Standard CD44 protein is comprised of four main domains: extracellular ligand binding, variable, transmembrane, and cytoplasmic (Figure 1B). Variable exon splicing mainly affects
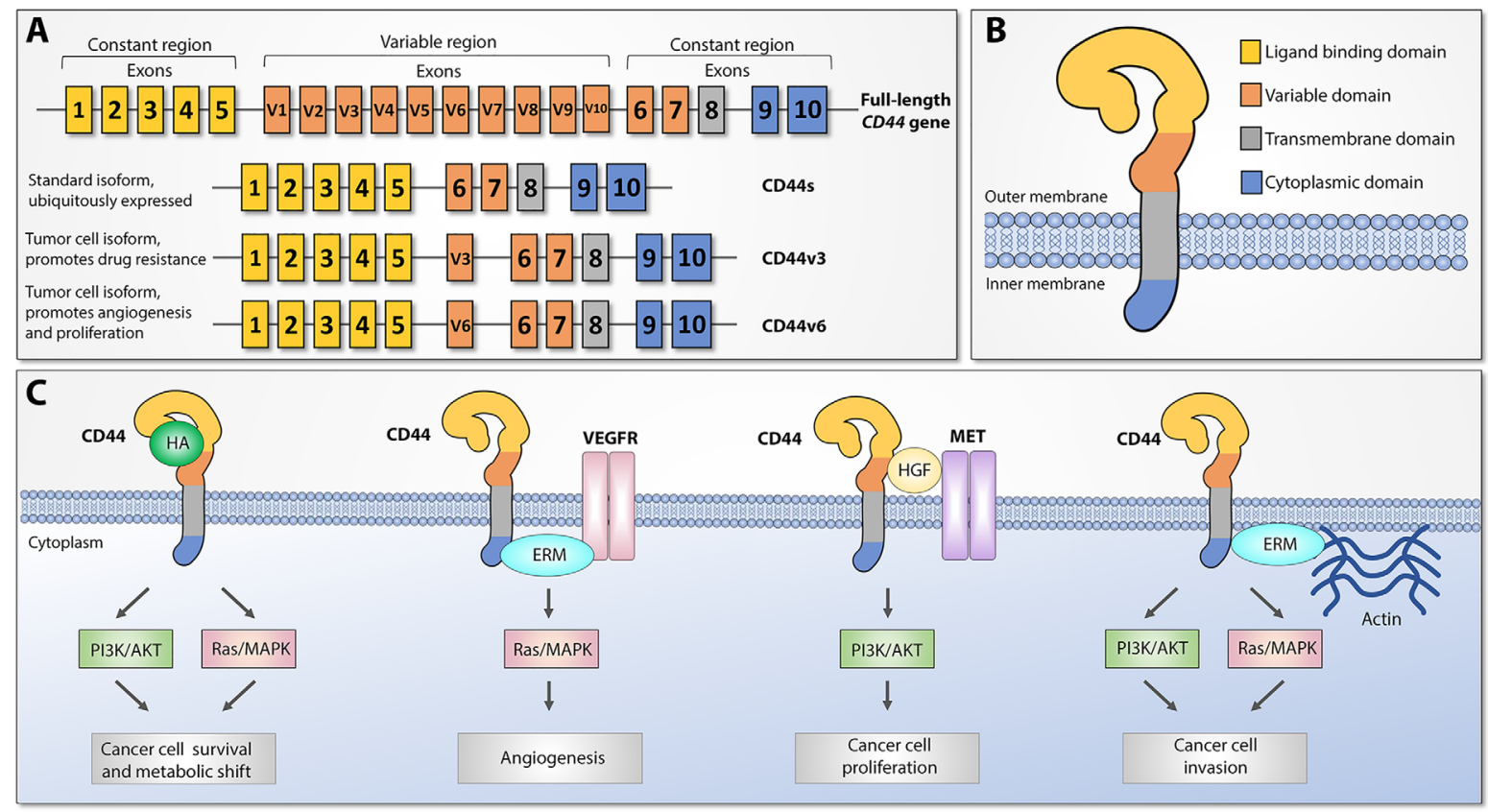

FIGURE 1 | CD44 structure and downstream signaling pathways, adapted from (12). (A) Top: CD44 gene structure. CD44 full-length pre-mRNA consists of 20 (mice) or 19 (human) exons, the first and last 5 of which are constant and 9-10 exons in the middle are variable (v) exons regulated by alternative splicing. Bottom: standard (CD44s) and most widely studied cancer-associated alternatively spliced variant isoforms (CD44v3 and CD44v6). Exon coloring parallels corresponding protein domains. (B) CD44 protein structure. Four main regions of the CD44 protein are presented with exon matching colors: constant extracellular ligand binding domain, variable extracellular domain, constant transmembrane domain, and cytoplasmic domain. (C) Main CD44-mediated downstream signaling pathways. Canonical CD44 activation relies on extracellular ligand stimulation, such as HA and subsequent PI3K and MAPK pathway activation, which leads to cancer cell metabolic shift and resistance to apoptotic stimuli. Via intracellular ERM protein recruitment, the cytoplasmic tail of CD44 can either interact with VEGFR and support tumor angiogenesis or promote cytoskeletal changes and promote cancer cell invasion. Additionally, CD44 may act as a coreceptor for several receptor tyrosine kinases, such as Met, to facilitate cancer progression. ERM: ezrin, radixin, and moesin. VEGFR: Vascular endothelial growth factor receptor. 
the structure of extracellular membrane-proximal regions of CD44 and up to ten different CD44v isoforms have been described (11-13). CD44s is present on the surface of most vertebrate cells and is typically described in the context of hematopoiesis (22).

CD44 proteins orchestrate diverse molecular functions in three main ways (Figure 1C). First, CD44 receptors serve as a non-kinase transmembrane receptor that can actively or passively bind ligands, such as hyaluronic acid (HA), ostepontin (OPN), collagen, fibrin, and others, and mediate interaction with the extracellular microenvironment (ECM). HA interaction leads to CD44 conformational changes that allow adaptor molecule binding to the intracellular cytoplasmic tail, which leads to activation of various signaling pathways, such as Ras/MAPK and PI3K/Akt, and facilitates cell proliferation, adhesion, and migration. Second, both CD44s and CD44v splice variants have been shown to act as a coreceptor to receptor tyrosine kinases (RTK), such as Met or the Epidermal Growth Factor (EGF) family ErbB, as well as stabilize other RTK complexes, such as receptors for vascular endothelial growth factor (VEGFR), which under pathological conditions leads to tumor progression, metastasis, and angiogenesis. Third, CD44 mediates cytoskeletal changes through interactions with actinbinding ERM (ezrin, radixin, and moesin) proteins, which are necessary for cellular movement and inducing either proliferationand metastasis-promoting signaling or proliferation- and metastasis-inhibitory molecular complexes, depending on extracellular signals. These findings indicate that CD44 proteins have highly conserved widespread biological functions, and under pathological conditions they may play an important role in promoting cancer progression, metastasis, and resistance to therapy (13).

\section{CD44 IN OVARIAN CANCER PROGRESSION AND THERAPY RESISTANCE}

Activated CD44 proteins interact with several intracellular signaling networks that support the oncogenic properties of tumor cells and drive cancer progression, metastasis, and therapy resistance across various cancer models (11, 12, 19, 23). Expression of different CD44 isoforms positively correlates with poor clinical outcome in various cancers, such as breast (24-26), colon (27), lung (28), bone (29), pancreatic (30), colorectal (31), bladder (32), gastric (33), and head and neck squamous cell carcinomas (34), as well as leukemias (35) and lymphomas (36). In line with these observations, CD44 has been increasingly implicated in the pathogenesis and poor clinical outcomes of ovarian cancer patients as well (37).

\section{CD44 Expression in Ovarian Cancer Progression and Metastasis}

CD44 expression has been found in most epithelial ovarian carcinoma (EOC) tumors and higher CD44 levels correlate with more advanced disease stage $(37,38)$. Several publications demonstrate the association of CD44 with poor prognosis in EOC patients $(37,39-42)$, including a recent systematic metaanalysis of 18 studies consisting of more than 2000 ovarian cancer patients, which showed a significant correlation between CD44 expression and poor 5-year overall survival (43). This demonstrates that CD44 levels are an effective marker for diagnosis and prediction of clinical outcomes. Importantly, upregulation of CD44 in ovarian cancer has been shown to be strongly associated with the occurrence of metastasis and disease relapse $(44,45)$. Specifically, Gao et al. analyzed patientmatched primary, metastatic, and recurrent tumor samples from 26 ovarian cancer patients and showed higher CD44 expression in metastatic and relapsed tumor tissues compared to patient-matched primary tumors, while at the same time CD44 knockdown significantly reduced proliferation and invasion capability of ovarian cancer cells in vitro (44). Additionally, several studies reported that CD44 expression was correlated with the epithelial to mesenchymal transition (EMT) phenotype in vitro and in patient samples. EMT is necessary for cells to detach from the epithelial layer and invade secondary sites to form metastases $(46,47)$. This study further confirms an important role for CD44 in ovarian cancer progression.

\section{CD44 in Ovarian Cancer Stemness and Chemoresistance}

CD44 surface expression has been linked to cancer stem cells (CSCs), in ovarian and other cancer models $(11,48,49)$, and most studies about the role of CD44 in ovarian cancer progression emphasize the connection between CD44 and CSC maintenance. CSCs are a regenerative tumor cell subpopulation that has attained stem cell-like properties, which allows these cells to drive tumor recurrence and chemoresistance. CD44 has been implicated as one of the potential biomarkers of ovarian CSCs $(48,50,51)$. CD44-positive (CD44+) ovarian tumor cell subpopulations have been shown to express stem cell markers and are able to initiate tumorigenesis and promote disease recurrence by recapitulating the original tumor $(52,53)$. More importantly in the context of this review, CD44+ stem-like cells have been shown to be markedly resistant to paclitaxel and platinum treatment, two standard front-line therapeutics against ovarian tumors (54). CD44+ and CD44-negative (CD44-) ovarian cancer cell fractions have been described as Type I chemoresistant and Type II chemosensitive EOC cells, respectively. Only cells expressing CD44 on the surface persist after chemotherapy treatment and are able to rebuild the tumor afterwards (55). Clinical studies of chemotherapy sensitive or resistant EOC patients show significant correlation between CD44 upregulation and chemotherapeutic drug resistance $(56,57)$, and numerous reports further confirm the role of CD44 in promoting chemoresistance in primary ovarian tumors, spheroids and ascites, as well as human ovarian cancer cell lines in vitro (51, $53,54,58)$. In line with these observations, drug resistant ovarian cancer cells show higher CD44 levels in vitro (44), while genetic 
overexpression of CD44s induces stem-like properties and chemoresistance in xenograft mouse models and ovarian cancer cell lines $(44,59)$. At the same time, CD44 knockdown significantly enhances paclitaxel, cisplatin, and doxorubicin sensitivity in ovarian cancer cells $(44,47,60)$. Collectively, these findings indicate a pivotal role for CD44 in therapy resistance development, which is currently a major challenge in the treatment of ovarian cancer patients. Identifying the precise molecular mechanisms of CD44 in promoting stem cell-like features and drug resistance would be highly advantageous in order to discover novel treatment strategies. However, due to the large number of signaling networks modulated by CD44, it is important to define relevant CD44 molecular interaction partners that aid in the promotion of ovarian tumor resistance to front-line therapeutics in clinic. Several studies identified STAT3 as an important interaction partner for CD44 in promoting tumor properties across various cancer models, including ovarian. Therefore, here, we evaluate all existing evidence indicating functional CD44 and STAT3 cooperation in the context of tumor metastatic progression, therapy resistance and immunosuppression with the focus on ovarian cancer. We will focus on tumor-specific and intracellular cross-regulation first, after which we will review and the ample evidence for CD44 and STAT3 crosstalk within the tumor microenvironment (TME) on the levels of new blood vessel formation, cancer-associated fibroblast activation and immunoregulatory cell recruitment. Finally, we will discuss CD44 and STAT3 involvement in cancer-driven metabolism switches and summarize currently available data on CD44 therapeutic targeting alone or in combination with STAT3, highlighting promising therapeutic opportunities for the future.

\section{CD44 AND STAT3 CROSSTALK IN CANCER}

STAT3 is a pleiotropic transcription factor that belongs to a family of STAT transcription factors and is involved in the regulation of numerous intracellular processes. Among the most well-known extracellular STAT3 activators are a large number of cytokines, chemokines and growth factors, as well as many tyrosine kinases that are upregulated in cancer. Traditional intracellular STAT3 activation involves tyrosine 705 phosphorylation by Janus kinases (e.g. JAK1, JAK2) or other tyrosine kinases as well as post translational modifications, such as acetylation, followed by nuclear translocation, where STAT3 binds to DNA and regulates the expression of target genes. Activated STAT3 is a critical contributor of cancer cell survival and proliferation, and tumor invasion, metastasis. STAT3 is also well-known to induce immunosuppression to promote tumor progression (61-63). Over the years, STAT3 has been shown to interact with several other transcription factors and signaling pathways at multiple levels to support cancer progression. One of such STAT3 interacting molecules is CD44. As with CD44, STAT3 signaling has been frequently implicated in ovarian cancer metastasis, therapy resistance, and CSC maintenance $(64,65)$. STAT3 transcriptional activity has been demonstrated to drive the migration and invasiveness of ovarian cancer (66-68). Specifically, activated STAT3 has been shown to induce matrix metalloproteinase 2 and 9 (MMP-2, MMP-9) expression in ovarian cancer models $(68,69)$, which are important factors involved in the degradation of extracellular matrix necessary for tumor invasion and metastasis (70). Moreover, STAT3 signaling promotes ovarian cancer resistance to cisplatin and paclitaxel, which can be reversed by either genetic or pharmacological STAT3 inhibition (71-74). Given that CD44 upregulation in patient samples and cell lines is also strongly correlated with an acquired resistance against the first line ovarian cancer therapeutics (53-57), we hypothesize that functional interaction between CD44 and STAT3 may be one of the driving mechanisms of ovarian cancer progression and therapy resistance, which deserves further attention. Below, we summarize currently existing evidence of functional and direct collaborations between CD44 and STAT3 signaling pathways across various cancer models.

During the last decade, several studies have shown that CD44 and STAT3 cooperate in cancer promotion. In the context of breast cancer, STAT3 signaling has been shown to be required for maintenance of self-renewal and growth of CD44+ breast CSCs (75). Additionally, siRNA-mediated STAT3 inhibition has been shown to reverse tamoxifen resistance of CD44+ breast CSCs, indicating a central role for STAT3 not only in CSC maintenance but also in therapeutic resistance development (76). Furthermore, numerous studies indicate that CD44 and STAT3 regulate each other's expression and activity. In prostate cancer, CD44 expression significantly correlates with IL-6, a STAT3activating cytokine, and IL-6 or STAT3 inhibition both decrease CD44 and EMT-related protein levels in cancer cell lines $(77,78)$. In agreement with these observations, monoclonal antibodies targeting the CD44s isoform reduce CSC percentage in cultured pancreatic cancer cells and in xenograft mouse models, along with downregulating STAT3 levels and STAT3-mediated target gene expression (79). In breast and urinary bladder cancer cell lines, CD44 knockdown inhibits cell invasion and tumorigenicity via STAT3 phosphorylation blockade, while anti-CD44 blocking antibody treatment downregulates STAT3 levels in rat atrial fibroblasts, suggesting that CD44 can regulate both STAT3 expression and activation (80-83). In turn, well known STAT3 activators IL-6 (84) and IGF-1 (85) have been shown to significantly induce CD44 promoter activity in pancreatic tumor cells (12), while in hepatocytes several putative STAT3 binding sites have been described within the CD44 promoter, demonstrating that STAT3 can directly induce CD44 expression (86). In line with these observations, STAT3 blockade via siRNA or specific inhibitors has been reported to significantly decrease CD44 expression in breast, prostate, nasopharyngeal, and gastric carcinoma models $(77,78,80,81,87,88)$. Collectively, these results show that CD44 and STAT3 can regulate each other's expression and cooperate across different tumor types to drive cancer invasion, metastasis, disease recurrence, and chemoresistance. Table 1 summarizes the data from published 
TABLE 1 | Reported cooperation between CD44 and STAT3 in different cancer models.

\begin{tabular}{|c|c|c|c|c|}
\hline Ref. & $\begin{array}{l}\text { CD44 } \\
\text { isoforms }\end{array}$ & Cooperation mechanism & Biological implications & Cancer type \\
\hline$(79)$ & CD44s & CD44 activates STAT3 via Nanog & $\begin{array}{l}\text { Tumor growth metastasis low survival rate, self-renewal } \\
\text { (CD44+CD24-) }\end{array}$ & Pancreatic cancer \\
\hline$(77)$ & CD44s & IL-6/STAT3 signaling promotes CD44 expression & $\begin{array}{l}\text { Increased colony formation, metastasis, tumor } \\
\text { aggressiveness }\end{array}$ & Prostate cancer \\
\hline (89) & CD44s & CD44 activates STAT3 via Nanog & Tumor progression, & Breast cancer Ovarian \\
\hline$(76)$ & & IL6/STAT3 signaling promotes CD44 expression & chemoresistance, stemness, migration and metastasis & cancer \\
\hline (81) & & CD44 induces hTERT via STAT3/NF-kB complex & & \\
\hline (86) & CD44s & IL6/STAT3 signaling promotes CD44 expression & Tumor progression, tumor growth & Liver Cancer \\
\hline (90) & $\begin{array}{l}\text { CD44, not } \\
\text { specified }\end{array}$ & $\begin{array}{l}\text { Nuclear CD44 binds acetylated STAT3 and promotes target } \\
\text { gene expression }\end{array}$ & $\begin{array}{l}\text { Cancer cell reprogramming, tumor progression, } \\
\text { metastasis }\end{array}$ & Colon cancer \\
\hline$(91)$ & CD44s & Concurrent expression of CD44 and STAT3 in patients & $\begin{array}{l}\text { Advanced tumor stage, } \\
\text { poor survival }\end{array}$ & $\begin{array}{l}\text { Clear renal cell } \\
\text { carcinoma }\end{array}$ \\
\hline (83) & $\mathrm{CD} 44 \mathrm{v} 3$ & $\begin{array}{l}\text { CD44 activates STAT3 along with PI3K and ERK signaling } \\
\text { cascades }\end{array}$ & Tumor survival and progression & Bladder cancer \\
\hline $\begin{array}{l}(87) \\
(92)\end{array}$ & CD44v6 & $\begin{array}{l}\text { IL6/STAT3 signaling promotes CD44 expression } \\
\text { CD44 expression increases cell survival via STAT3 and P38 }\end{array}$ & $\begin{array}{l}\text { Tumor growth, invasion, metastasis, progression and } \\
\text { chemoresistance }\end{array}$ & Gastric Carcinoma \\
\hline$(78)$ & $\begin{array}{l}\text { CD44, not } \\
\text { specified }\end{array}$ & STAT3 signaling promotes CD44 expression & Resistance to anoikis, invasiveness, metastasis & $\begin{array}{l}\text { Nasopharyngeal } \\
\text { carcinoma }\end{array}$ \\
\hline
\end{tabular}

studies in which different CD44 isoforms were shown to cooperate with STAT3 in different cancer models. (76-79, 81, $83,86,87,89-92$ )

Additionally, several direct intracellular interactions between CD44 and STAT3 have been reported across different cancer models. In breast cancer cells, transmembrane CD44 isoforms have been shown to either physically associate directly with JAK2 and STAT3 to induce conventional STAT3 oncogenic signaling (80) or activate STAT3 in the cytoplasm to form a complex with NF-kB p65 subunit in order to initiate the transcription of human telomerase reverse transcriptase (hTERT), which further leads to EMT and breast CSC phenotype maintenance (81). Next, across various cancer models, full-length CD44 has been shown to translocate to the nucleus, physically bind to nuclear STAT3 and p300 acetyltransferase, and promote STAT3 acetylation at lysine 685, which elicits cell proliferation and stem cell-like phenotype in colon, gastric, and lung cancer cell lines $(90,93)$. Co-IP experiments showed that the coiled-coil domain of STAT3 and C-terminal domain of CD44 are important for CD44/STAT3 complex formation. Finally, Bourguignon and colleagues showed that HA-induced CD44 activation promoted STAT3/Nanog complex formation, which led to the upregulation of multidrug resistance marker MDR1 in breast, ovarian, and head and neck squamous cell cancers $(89,94)$. In line with these observations, we have previously shown that CD44 promotes multidrug resistance and MDR1 stabilization in ovarian cancer cells $(95,96)$, while STAT3 signaling has been shown to induce MDR1 expression in ovarian, lung and bone cancers, as well as a myeloid leukemia model (97-100). All reported CD44 and STAT3 intracellular interactions are graphically summarized in Figure 2.

Taken together, these findings indicate that the promotion of metastasis, stem cell-like phenotype, and chemoresistance involves intracellular cooperation between CD44 and STAT3 on a molecular level across numerous cancer models, including ovarian. Therefore, CD44 and STAT3 crosstalk deserves further investigation to identify promising novel strategies to sensitize ovarian tumors to treatment and prevent disease relapse.

\section{CD44 AND STAT3 IN OVARIAN TUMOR MICROENVIRONMENT}

Cancers encompass not only masses of malignant tissue but also recruit and exploit different types of non-transformed cells. The tumor microenvironment (TME) refers to the surrounding stroma where tumor grows and complex biological interactions between malignant and non-transformed cells occur. Nonmalignant cells present within the TME often demonstrate tumor-promoting functions and further facilitate disease progression, immunosuppression, and metastasis (101-103). Functional interaction between CD44 and STAT3 can also occur at different levels of the TME, discussed in detail below, and encompass tumor endothelial cells, fibroblasts, and cells of the immune system, such as myeloid-derived suppressor cells, macrophages, and regulatory $\mathrm{T}$ and $\mathrm{B}$ cells.

\section{CD44 and STAT3 in Endothelial Cells for Tumor Angiogenesis}

New blood vessel formation is required for blood supply to satisfy oxygen and nutrient demands of tumor tissues. This is achieved through a process called angiogenesis, where hypoxic conditions stimulate vascular endothelial growth factor (VEGF) secretion and start a multidimensional process regulated by cancer cells in concert with various immune cells, fibroblasts, and other TME cells that results in the growth of new blood vessels, which further supports tumor survival and induction of metastasis (104, 105). At the molecular level, both CD44 and STAT3 have been reported 


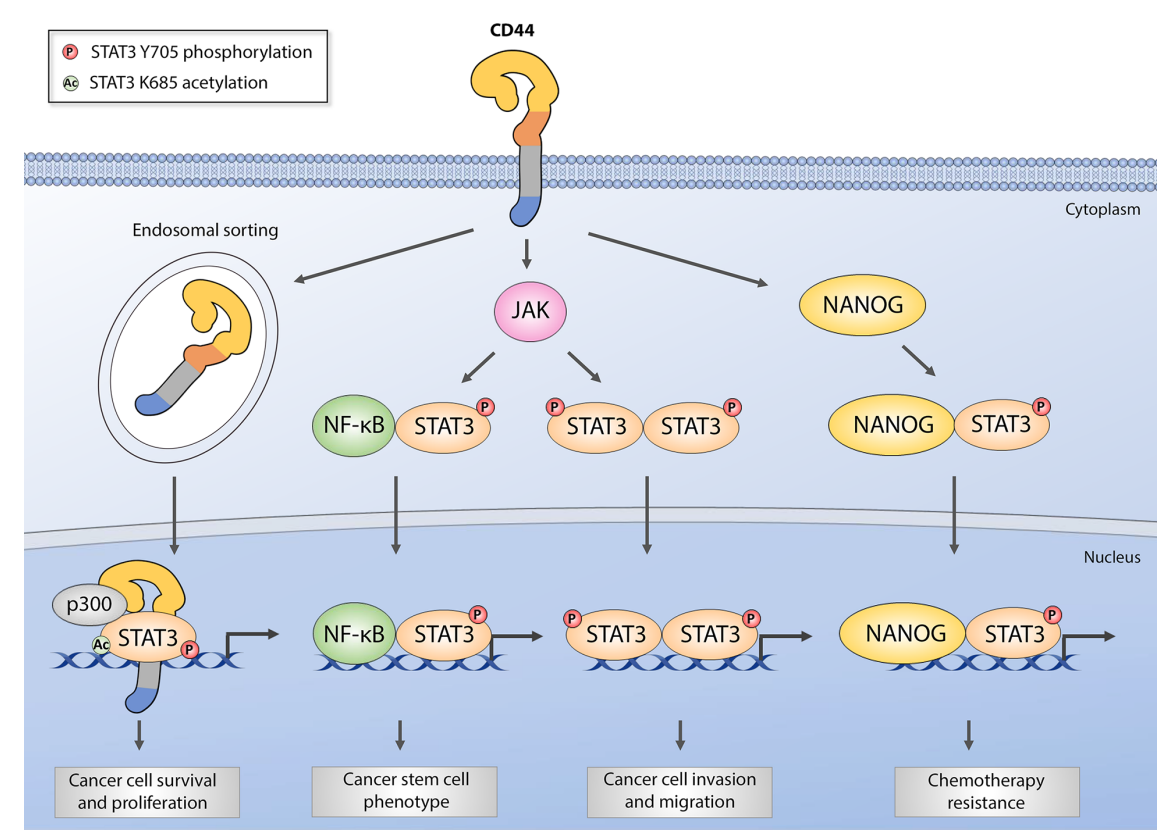

FIGURE 2 | Graphical representation of intracellular CD44 and STAT3 interactions in various cancer models. Full-length CD44 can translocate to the nucleus via endosomal sorting and form nuclear complexes with histone acetyltransferase p300 and STAT3, which supports STAT3 phosphorylation and acetylation and subsequent pro-tumorigenic gene induction. Membrane-bound CD44 isoforms are capable of inducing canonical JAK-mediated STAT3 activation by critical tyrosine 705 phosphorylation, leading to either classical activated STAT3 dimer formation and target gene induction, or formation of nuclear NF-kB and STAT3 complex critical for cancer stem cell gene expression. Finally, HA-mediated CD44 activation has been shown to promote cytoplasmic NANOG/STAT3 complex formation involved in multiple drug resistance gene upregulation and chemoresistance.

to support tumor angiogenesis in several tumor models. Numerous studies provide evidence of the involvement of endothelial cell-associated HA/CD44 signaling in normal angiogenesis (106-109). In the context of tumor vascularization, epithelial cells from the blood vessels of solid tumors show increased CD44 levels compared with normal tissue samples $(110,111)$, and CD44 inhibition blocks tumor induced angiogenesis in human melanoma and laryngeal cancer models (112). Moreover, high CD44 expression levels are significantly correlated with increased VEGF and both factors are associated with an adverse prognosis for renal cell carcinoma patients (113). Finally, endothelial CD44 has been shown to be essential for wound healing and vascularization, as well as ovarian tumor angiogenesis in vivo (114). Likewise, ample evidence suggests that STAT3 regulates many aspects of tumor angiogenesis at the transcriptional level (115). Our group and others previously demonstrated that STAT3 is an essential mediator of endothelial activation by directly inducing VEGF and HIF1a gene expression $(116,117)$. On a functional level, STAT3 signaling has been reported to promote angiogenesis in human pancreatic, lung, and breast cancers (118-120) and we have previously shown that STAT3 is a critical regulator of the pro-angiogenic functions of myeloid cells in mice (121). In ovarian cancers, the expression of VEGF and its receptors VEGFR1 and VEGFR2 significantly correlate with pSTAT3 levels in patient samples
(122), and STAT3 and VEGF have been shown to reciprocally regulate each other's expression and activation in EOC models $(123,124)$.

Furthermore, both CD44 and STAT3 have been shown to crosstalk with matrix metalloproteinases, which are important mediators of tumor angiogenesis (125). We and others have previously demonstrated that CD44 signaling upon HA or OPN treatment stimulated the synthesis of MMP-2 and MMP-9, which facilitated extracellular matrix degradation and subsequent disease progression (126-129). In cancer cell line models CD44+ cells demonstrated significantly elevated MMP-2 and MMP-9 levels compared to CD44- cells, further indicating that CD44 is involved in MMP-2 and MMP-9 expression (130). Apart from that, CD44 also plays an important role in MMP-2 and MMP-9 activation through the binding of proteolytically active MMP-2 and MMP-9 isoforms to the membrane and promoting the cleavage of latent TGF- $\beta$, which led to invasion and angiogenesis across various cancer models (131-133). Similarly, STAT3 also promotes the expression of matrix metalloproteinases MMP-2 and MMP-9, as well as basic fibroblast growth factor (bFGF) genes, which are also implicated in new blood vessel formation $(118,134,135)$. However, despite both STAT3 and CD44 acting as pivotal regulators of tumor angiogenesis, there is currently no direct evidence of functional crosstalk between STAT3 and CD44 during angiogenesis promotion. One potential indication of 
CD44 and STAT3 cooperation in new blood vessel formation is an observation made by Wang and colleagues (124). They reported that $\mathrm{HA} / \mathrm{CD} 44$ signaling promoted epithelial tube and new blood vessel formation via activation of Src that in turn enhanced expression of c-Jun and c-Fos transcription factors. Our laboratory and other groups have previously established Src kinases as important upstream activators of STAT3 during oncogenesis (136-139), while c-Jun and c-Fos have been shown to form a complex with STAT3 that binds to IL6 response elements $(140,141)$, indicating that CD44 and STAT3 may cooperate in new blood vessel formation. The numerous observations that both CD44 and STAT3 are critically involved in the VEGF pathway and tumor angiogenesis indicate that dual targeting of both factors could be a promising therapeutic target to improve antiangiogenic treatment in ovarian cancer. Given that increased angiogenesis has been shown to be associated with cancer therapy resistance in ovarian cancer ascites (142), targeted inhibition of new blood vessel formation by ovarian tumors will aid in improving therapy outcomes.

\section{CD44 and STAT3 in Cancer-Associated Fibroblasts}

Under normal conditions, resident tissue fibroblasts support tissue integrity and homeostasis. Cancer-associated fibroblasts (CAFs) are an immensely heterogenous stromal cell subpopulation that resides in the TME and hijacks normal physiological functions of fibroblasts to drive solid tumor growth, angiogenesis, and inhibition of anti-tumor immune responses $(143,144)$. In ovarian cancer, CAFs are prominent components of the ovarian TME and have been shown to support cancer cell proliferation and metastasis by inducing EMT and angiogenesis, as well as immunosuppression and the cancer cell metabolism switch (145). More importantly, CAFs also promote the CSC phenotype and chemoresistance development in ovarian tumor models $(145,146)$ and several studies have demonstrated that CD44 and STAT3 signaling pathways are involved in CAF-mediated therapy resistance. CD44+ ovarian cancer tumors have been shown to reside near tumor stroma. Our immunohistochemical analysis of CD44 expression in EOC patients indicated CD44 involvement in a functional crosstalk between tumor and surrounding stroma (55, 147). In line with these observations, TGF- $\beta$-activated versican expression in CAFs has been shown to induce the remodeling of ECM and ovarian cancer cell invasion by upregulation and binding to CD44 in ovarian cancer cells (148). At the same time, ovarian CAFs have been shown to be a major source of IL-6 in the TME, which activates STAT3 in ovarian tumor cells leading to cell proliferation and invasion (149). CAF-mediated STAT3 activation in ovarian cancer lines also leads to development of cisplatin resistance through the increased expression of antiapoptotic proteins, indicating a prominent role for STAT3 in CAF-induced chemoresistance (150). In the context of ovarian carcinoma, there are no reports analyzing CD44 or STAT3 signaling within CAFs themselves. However, both high CD44 expression and STAT3 activation in CAFs have been reported to maintain CSC phenotype and promote cancer drug resistance in other cancer types (151-155). Additionally, TGF- $\beta$, an important mediator of normal fibroblast transition into ovarian CAFs $(143,148)$, upregulates CD44 and STAT3 in cultured rat atrial fibroblasts to promote atrial fibrosis (82). Therefore, it is reasonable to postulate that CD44 and STAT3 not only mediate CAF-driven ovarian tumor stemness and chemoresistance within tumor cells, but also cooperate within CAFs themselves to support their cancer-promoting phenotype, which requires further investigation.

\section{CD44 and STAT3 in Myeloid-Derived Suppressor Cells}

Myeloid-derived suppressor cells (MDSCs) represent another major component of the TME and are well known in cancer immunology research for their strong immunosuppressive activity. Like CAFs, MDSCs are a heterogenous cell population consisting of myeloid progenitors and immature macrophages, granulocytes, and dendritic cells. Under normal conditions, immature myeloid cells (IMCs) terminally differentiate into specific immune cell subsets via a process called myelopoiesis in order to protect the host from pathological conditions. However, during cancer progression and low-level chronic inflammation, IMCs fail to terminally differentiate and give rise to MDSCs that migrate to peripheral lymphoid organs and accumulate within the TME and tumor tissues to further support cancer progression. MDSCs are phenotypically classified as monocytic (M-MDSCs) or granulocytic and polymorphonuclear (G-MDSC/PMN-MDSC) MDSC populations and their upregulation and function correlate with progression, recurrence, and therapy resistance of many types of human tumors (156-158). Several reports show MDSC involvement in ovarian cancer progression. In two different publications, MDSCs have been shown to drive immunosuppression in the ID8 ovarian cancer mouse model either by directly downregulating cytotoxic CD8+ T cells or by inducing immunoregulatory CD4+CD25+ Treg cell expansion (159, 160). Apart from suppressing anti-tumor immunity, MDSCs have also been demonstrated to drive CSC gene expression, sphere formation, and metastasis of primary human ovarian cancer cells (161). Since numerous studies show that increased numbers of tumor MDSC are a significant and independent predictor of poor survival rates of ovarian cancer patients (161-165), targeted inhibition of MDSCs and underlying molecular mechanisms could be a promising treatment approach.

Both CD44 and STAT3 have been shown to support protumorigenic MDSC functions. Only high CD44-expressing head and neck squamous carcinoma cells can efficiently induce MDSCs and Treg accumulation (166), while physical interaction of peripheral blood monocytes (PBMCs) with CD44 expressed on the surface of activated hepatic stellate cells leads to monocyte trans-differentiation into MDSCs (167). At the same time, STAT3 has been described as the main transcription factor that drives the expansion and function of MDSCs. Compared to naïve IMCs, MDSCs from tumor-bearing mice demonstrate increased levels of STAT3 activation (168), and JAK2/STAT3 pathway plays an essential role in MDSC expansion from hematopoietic progenitor cells. Namely, 
targeted STAT3 blockade or conditional hematopoietic STAT3 knockout in mice significantly reduces MDSC population and increases T-cell responses, as we and others have previously shown $(169,170)$. Notably, tumor-induced STAT3 activation in the M-MDSC subpopulation increases CD44 expression in human pancreatic cancer cells and promotes CSC-like properties (171), indicating that STAT3 transcriptional activity in MDSCs functionally interacts and relies on CD44 signaling to promote cancer stemness and immunosuppression. Because MDSCs promote both ovarian cancer cell stemness and accumulation of ascites in ovarian cancer via STAT3 (172), we propose that targeting STAT3 along with CD44 in ovarian tumors may be a rational strategy for blocking MDSC-driven immunosuppression and enhancing the efficacy of conventional ovarian cancer therapy.

\section{CD44 and STAT3 in Tumor-Associated Macrophages}

Tumor-associated macrophages (TAMs) are the main population of immune cells in ovarian tumor stroma, and CD44 and STAT3 both significantly contribute to tumor promoting properties of the ovarian TME (173). TAMs are either mature macrophages that are recruited to the tumor site and surrounding tissues or they can differentiate from M-MDSC already present within the TME (174, 175). TAMs can have both tumor supportive or inhibitory properties, which mainly depends on TAM polarization into either pro-inflammatory antitumor M1 or immunosuppressive, tumor-promoting M2 phenotype (176). In the TME, persistent STAT3 activation has been shown to suppress the M1 phenotype and promote anti-inflammatory M2 polarization of TAMs, which further promotes tumor growth by enhancing angiogenesis, immunosuppression, cancer cell invasion, and metastasis of several cancer models (177-179). More importantly for the scope of this review, tumor-promoting TAMs have been reported to drive ovarian cancer metastasis, stemness, and therapy resistance with the involvement of STAT3 and CD44. In EOC patients, higher M2 TAM accumulation positively correlates with shorter survival rate (180) and STAT3 activators IL-6 and LIF have been shown to drive M2 TAM phenotype switch in ovarian tumors (181). In line with these reports, ascites from EOC, but not from non-EOC patients, induce M2 macrophage polarization through STAT3 activation (182), indicating a central role for STAT3 in M2 TAM expansion in ovarian tumors. Furthermore, TAM interactions with CD44+ ovarian CSCs have been shown to promote ovarian cancer recurrence and multidrug resistance (183), and a recent study showed that not only increased STAT3 signaling within TAMs can induce CD44 expression and CSC-like phenotype in ovarian cancer cells, but high CD44-expressing ovarian CSCs are able to further promote the M2 phenotype through STAT3 activation in macrophages as well, forming a positive feed-forward loop of mutual TAM and CSC activation via CD44/STAT3 cooperation that results in ovarian cancer stemness maintenance and chemoresistance (184). Collectively, these observations support a prominent role for CD44 and STAT3 crosstalk in mediating tumor and TAM interactions within the ovarian TME.

\section{CD44 and STAT3 in Regulatory T Cells}

Regulatory $\mathrm{T}$ cell (Treg) accumulation and suppression of antitumor immunity have been shown in ovarian cancer mouse models, and Tregs are linked to poor prognosis for ovarian cancer patients $(62,185-188)$. Several studies have demonstrated significant accumulation of activated regulatory Tregs in ascites and tumor tissues from ovarian cancer patients compared with normal ovarian tissue $(186,189)$. These studies demonstrate that Tregs in the malignant ascites are more activated and have a higher proliferation rate compared to blood-derived cells from the same patients. A recent study showed that Treg cells isolated from ovarian tumors display a distinct cell surface phenotype with increased expression of immunosuppressive receptors, such as PD-1, 4-1BB, and ICOS (187). In addition, high expression of FoxP3, a master regulator of the Treg immunosuppressive phenotype, is associated with poor prognosis in ovarian cancer patients (190).

Despite the progress made in studying Treg activation in ovarian cancer, relatively little is known about the underlying molecular mechanisms. Several studies have implicated CD44 involvement, which is frequently expressed and activated in Tregs. CD44 expression is positively correlated with FoxP3 expression and the suppressive function of Tregs (191), while Treg-specific CD44 depletion enhances antitumor immunity (192) and CD44-knockout mice display functionally impaired Tregs (193). STAT3 has also been confirmed as a critical molecular driver for FoxP3 expression and Treg immunosuppressive phenotype in the tumor setting $(194,195)$. Based on these studies, CD44 and STAT3 have overlapping functions within tumor-associated regulatory $\mathrm{T}$ cells. Indeed, while CD44 co-stimulation promotes the expression of FoxP3 and supports Treg function via IL-2, IL-10, and TGF- $\beta$ production (193), FoxP3 has been shown to act as a cotranscription factor with STAT3 in tumor-induced Tregs to promote immunosuppressive IL-10 production (196), suggesting that functional CD44 and STAT3 cooperation is one of the main molecular mechanisms that drives Treg immunosuppressive actions.

\section{CD44 and STAT3 in Regulatory B Cells}

Regulatory B cells may promote cancer progression, mainly by IL10 mediated cytotoxic T cell inhibition. Accumulating evidence has indicated that B cells are involved in ovarian cancer progression (197-199). It has been shown that STAT3 is constitutively active in tumor-associated B cells (200). Furthermore, our group previously reported that CD5 in tumor infiltrating B cells binds to IL-6, and through gp130 induces STAT3 activation to promote cancer development (201). Our previous studies also showed that increased B cell infiltration and p-STAT3 expression in omental tissue are associated with poor survival in ovarian cancer patients (202). Finally, functional CD44/STAT3 crosstalk in human immunoregulatory B cells is further highlighted through the observation that CD44 ligation on B-cells significantly upregulates STAT3-activating IL-6 gene expression (203). 
Taken together, these findings demonstrate that the ovarian TME is a complex multicomponent system that is dynamically supported by different cell types and a variety of underlying molecular mechanisms, including CD44 and STAT3 signaling pathways. The summary of reported CD44 and STAT3 interactions within the TME is visually presented in Figure 3. Collectively, these data may inspire a new wave of clinical investigation that will provide important insights into the clinical benefits of eliminating immunosuppression and preventing therapy resistance of ovarian cancer by targeting the CD44/STAT3 axis in different TME resident cell types.

\section{CD44 AND STAT3 IN OVARIAN CANCER METABOLISM}

Metabolism rewiring is a hallmark of cancer progression across numerous tumor models (204). Below, we discuss potential roles for CD44 and STAT3 in different aspects of metabolism switch in cancer cells that support tumor progression. Specifically, we highlight available findings on potential CD44 and STAT3 cooperation in promoting glycolysis or lipid catabolism.

\section{CD44 and STAT3 in Glycolysis}

Enhanced glycolysis, known as the Warburg effect (WE), fulfils high energy demand and provides metabolic intermediates involved in synthesis of building blocks for cancer growth, progression, and chemoresistance. WE is widely believed to predominate in many cancers, including ovarian $(205,206)$. CD44 is suggested to regulate glucose metabolism by switching metabolic pathway to elevated glycolysis and increasing energy production via interacting with the glycolytic enzyme PKM2 in cells either with p53 deficiency or under hypoxic conditions. Depletion of CD44 sensitizes colorectal cancer cells to chemotherapeutics potentially due to accumulated cellular reactive oxygen species (ROS) (207). Furthermore,

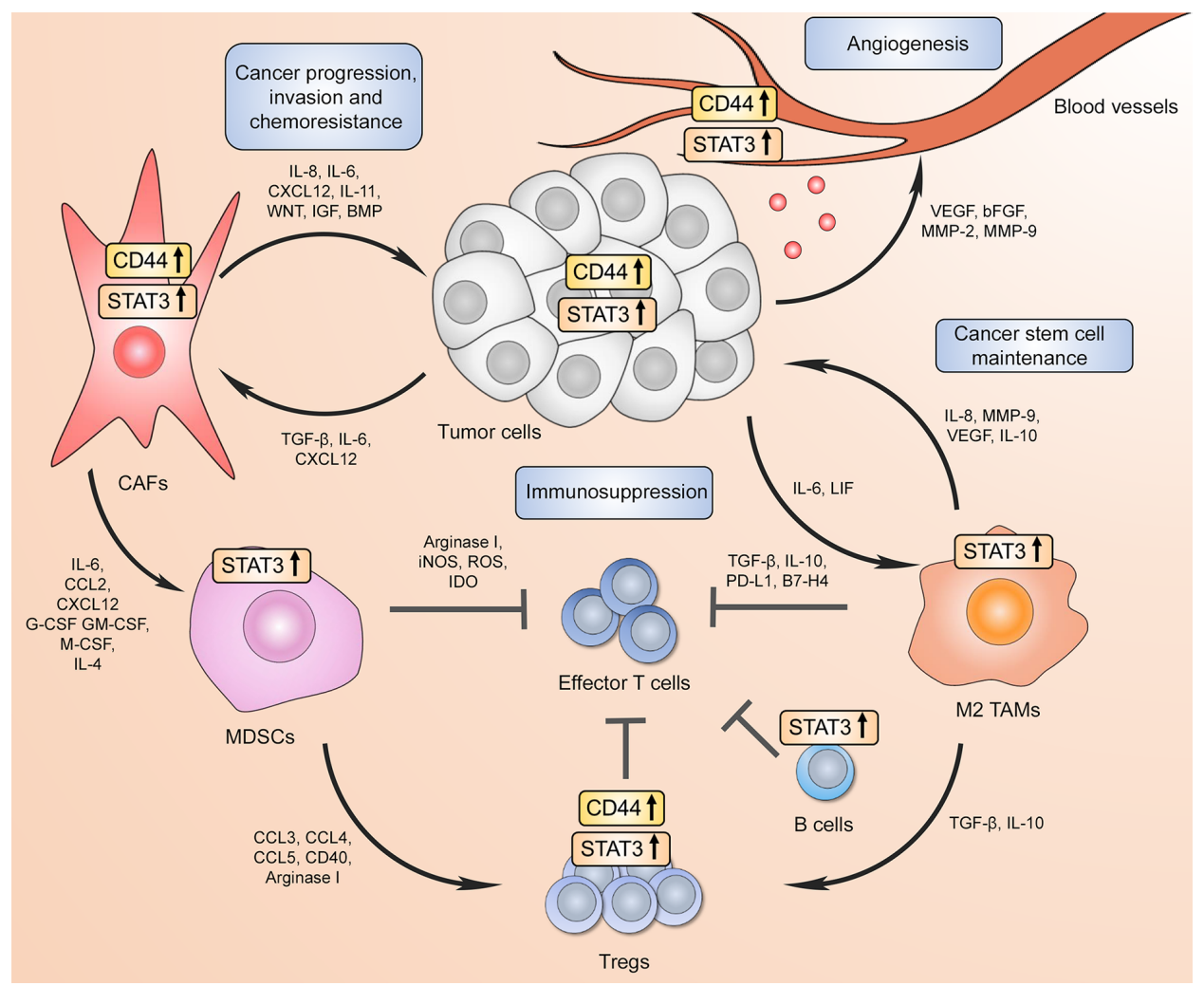

FIGURE 3 | CD44 and STAT3 support the communication between tumor cells and the tumor microenvironment (TME) to drive cancer progression/recurrence, immunosuppression, and chemoresistance. Increased CD44 and STAT3 activity in tumor cells promotes proximal cancer-associated fibroblast differentiation, which in turn further supports tumor progression through pro-tumorigenic factor secretion forming a positive feed-forward loop. In addition, CD44 in both cancer cells and CAFs facilitate the expansion and recruitment of myeloid-derived suppressor cells (MDSCs) that either directly inhibit cytotoxic effector CD8+ T cell function or drive immunoregulatory T cell (Treg) differentiation. Both CD44 and STAT3 contribute to tumor Treg expansion through upregulating FoxP3 expression. High STAT3 activation in B cells also results in immunosuppressive phenotype. At the same time, tumor-associated macrophages (TAMs) in the TME have also been shown to repress effector T cell-mediated anti-tumor immunity through immunosuppressive cytokine production and immune checkpoint expression, which requires STAT3 transcriptional activity. Moreover, increased STAT3 signaling in tumor surrounding TAMs promotes cancer stem cell phenotype, which in turn further drives immunosuppressive macrophage phenotype. Finally, CD44 and STAT3 signaling in both tumor and endothelial cells contributes to new blood vessel formation via angiogenic factor expression. 
overexpression of CD44 enhances glycolytic activity in the highly aggressive prostate small cell neuroendocrine carcinoma (SCNC) via PFKFB4 upregulation, whereas knockdown of CD44 by RNA interference increases the sensitivity of SCNC cells to carboplatin (208). In breast cancer, the dependency on glycolysis for CD44+ CSCs has been demonstrated by the enrichment of essential enzymes of glycolysis for maintaining cancer stem-like properties under hypoxic conditions (209, 210). The mechanistic study performed by Nam et al. further confirmed CD44-mediated regulation of glycolysis in breast cancer cells via $\mathrm{LDH} 1$ isoform upregulation by the CD44-activated c-Src/Akt/LKB1/AMPK $\alpha$ signaling pathway (211). The activation of HIF- $1 \alpha$ associated signaling cascades by CD44 also contributes to enhanced glycolytic phenotype (212). Of interest, CD44+ ovarian CSCs show preference for glycolysis as well, which indicates an important role for CD44 in ovarian cancer stemness maintenance via metabolism regulation (213). Likewise, many laboratories have shown that STAT3 promotes glycolysis by upregulating HIF-1 $\alpha$ and consequently inducing glycolytic gene (e.g. PKM2) expression across various tumors (214-216). The ability of both CD44 and STAT3 to activate HIF- $1 \alpha$ associated pathways may suggest their concomitant impact on glucose metabolism during ovarian cancer progression.

\section{CD44 and STAT3 in Lipid Metabolism}

In addition to the effects of elevated glycolysis on cancer cells, mounting evidence has recently demonstrated the importance of lipid metabolism in promoting cancer aggressiveness, metastasis, and chemoresistance (217-219). First, facilitating exogeneous fatty acid uptake from visceral adipocytes through elevated fatty acid receptor CD36 on ovarian cancer cells contribute to tumor progression and peritoneal metastatic module formation (220). Second, ovarian cancer reprogramming towards upregulated lipogenesis supports tumor growth and metastasis in the omental and ascitic microenvironments (221). Finally, catabolism of fatty acids mainly through fatty acid $\beta$-oxidation (FAO) promotes ovarian cancer malignant transformation by overexpression of $\mathrm{CPT} 1 \mathrm{~A}$, an isoform of CPT1, which is a rate limiting enzyme involved in FAO (222).

Intriguingly, CD44 signaling has been implicated in lipid metabolism during malignant progression. Inhibition of FASN and ACLY, the key enzymes regulating de novo lipid synthesis, significantly downregulates CD44 expression and disrupts the CD44/c-MET complex formation, which suppresses the activation of downstream Src-mediated signaling that modulates cell proliferation and invasion (223). However, despite the reliance of CD44+ CSCs on glycolysis, recently emerged evidence demonstrates CSC tendency to rely on the energy-efficient oxidative phosphorylation (OXPHOS) route as well. The CD36 overexpressing CD44+ cells possess an increased metastasisinitiating potential, which is highly dependent on the absorbed fatty acids as an energy source compared to the low CD36 nonmetastatic counterparts (224). Also, CD44+ breast CSCs not only show high lipid droplet accumulation (225), but also require FAO for maintenance of self-renewal and chemoresistance through JAK/ STAT3 mediated induction of CPT1B, another isoform of CPT1, as recently demonstrated by our group (226). Similarly, CD44+ CSCs derived from ovarian cancer patients show both upregulated glucose uptake and the expression of key genes associated with OXPHOS and FAO (227). The contradictory findings about the metabolism state of CD44+ CSCs may be ascribed to the existence of differential subpopulations of CD44+ cells, which display highly heterogenous gene expression profiles that determine metabolic preference and, therefore, cell fate. Understanding the metabolic characteristics associated with therapy resistance and uncovering the underpinning mechanisms, such as CD44 and STAT3 crosstalk, will provide insight into novel therapeutic interventions to overcome ovarian cancer chemoresistance.

\section{CD44 TARGETING FOR CANCER THERAPY}

Targeted therapies are intended to specifically inhibit abnormally activated pathways within cancer cells and represent a better and more precise treatment option than conventional chemotherapy. While CD44 expression is almost undetectable on normal ovarian surface epithelium $(47,228,229)$, the majority of epithelial ovarian carcinomas demonstrate high CD44 levels (38-40), which is correlated with disease progression, cancer stemness and resistance to therapy $(44,48,55)$. As discussed above, the multifunctional roles of CD44 in dynamic interactions between tumors and the TME, as well as in the regulation of cancer metastasis, stemness, and chemoresistance make CD44 an attractive therapeutic target to improve clinical outcomes for ovarian cancer patients by sensitizing them to chemotherapy. Below, we review different approaches to block CD44 signaling in pre-clinical studies and highlight the outcomes of different CD44 targeting clinical trials, as well as provide additional evidence for the potential benefits of dual targeting of CD44 and STAT3.

\section{CD44 Targeting in Pre-Clinical Studies}

The main types of therapeutics that are aimed to target CD44 in tumors in both preclinical and clinical trials are neutralizing monoclonal antibodies (Mabs), HA-conjugates, and peptide mimetics (12). CD44-targeting antibodies showed a significant anti-tumor effect in xenograft pancreatic and squamous cell carcinoma models, as well as in acute myeloid leukemia (AML) (79, 230, 231). Moreover, a recombinant humanized Mab, RG7356, that selectively recognizes the HA-binding region of all CD44 isoforms, demonstrated promising results in preclinical studies by selectively killing leukemic B cells without affecting the viability of normal B cells in a chronic lymphocytic leukemia (CML) model (232), indicating a potential for Mabs for cancer treatment in clinic. As an alternative strategy to antibodies, HA-conjugated chemotherapeutics were formulated to specifically target tumor cells for more precise action and side-effect minimization. HA-conjugated paclitaxel has been shown to selectively bind CD44+ tumor cells and block cancer cell line proliferation in vitro of numerous cancer 
types, including ovarian $(233,234)$. Finally, specific peptides that mainly target HA-CD44 interaction have been reported. Specifically, CD44-binding peptide A5G27 showed significant inhibitory effect on tumor growth and metastasis in a mouse melanoma model (235), while another CD44-targeting peptide, A6, inhibited migration, invasion, and metastatic potential of prostate, breast and ovarian cancer cells (236-238). Taken together, numerous studies demonstrate the beneficial effects of CD44 inhibition on tumor progression. This supports CD44 as a promising clinical target for the development of novel ovarian cancer therapeutics.

\section{Combined CD44 and STAT3 Inhibition}

Relevant to the scope of this review, several studies have demonstrated beneficial effects of combined CD44 and STAT3 signaling downregulation across different cancer models, including ovarian cancer. Gemini vitamin D analogue BXL0124 inhibits CD44-STAT3-mediated breast cancer invasion and metastasis by decreasing CD44 expression and STAT3 activation, as well as preventing CD44 binding to JAK2 and STAT3 in the cytoplasm (80). Likewise, Zerumbone, a monocyclic natural anti-inflammatory and antioxidant agent, suppresses EGF-induced CD44 expression through STAT3 pathway inhibition in breast cancer cell lines, while combined STAT3 and NF-kB inhibition with curcumin and epigallocatechin gallate decreases the CD44+ breast CSC population $(88,239)$. More importantly, in ovarian cancer cells, a natural compound from Tripterygium wilfordii, Celastrol, promotes apoptosis by decreasing CD44 expression and STAT3 phosphorylation (240). Additionally, ovarian cancer cell stemness is reduced by the FK506-binding protein like (FKBPL) peptide via inhibiting the CD44/STAT3 signaling axis (241) and the medicinal herb corilagin sensitizes human ovarian cancer cell lines to chemotherapy by glycolysis inhibition via downregulation of both CD44 and STAT3 expression (242). Finally, an orally administered small molecule STAT3 inhibitor Napabucasin, which is currently being tested in several clinical trials against various cancer models (243), have been shown to decrease both STAT3 activation and CD44 expression in biliary tract cancer cells (244). Collectively, these observations indicate that CD44 and STAT3 molecular cooperation deserves further attention and may be a promising clinical target to develop more effective therapeutics for the treatment of ovarian tumors. Given that CD44/STAT3 axis is involved in cancer progression and therapy resistance, we hypothesize that combinatorial administration of the most promising targeting agents, such as A6 blocking peptide against CD44 and Napabucasin against STAT3, can be beneficial for ovarian cancer patients in advanced disease stage and deserves further investigation.

\section{CD44 Targeting in Clinical Trials}

To date, several clinical trials have tested different CD44 targeting agents to generate a cancer-specific drug delivery system in the clinic. The outcomes of different trials analyzing CD44-targeting agents are summarized in Table 2 (245-254).

Thus far, clinical trials of targeted CD44 therapies have focused on either humanized or immunoconjugated Mabs, such as RG7356 and Bivatuzumab, respectively, HAconjugated chemotherapeutics, or CD44-targeting peptide A6 also known as SPL-108. As seen in Table 2, Bivatuzumab, a CD44-specific Mab conjugated with mertansine, demonstrates severe adverse effects related to serious skin toxicity with fatal outcomes $(245,246)$. Humanized RG7356 antibody shows mild adverse effects and was well tolerated in advanced solid malignancy and AML trials, however solid tumor clinical response showed only $21 \%$ efficacy $(249,250)$. As an alternative to antibodies, a specific drug formulation covalently attached to HA has been tested. HA-bound irinotecan, a topoisomerase-1 inhibitor, utilizes the unique biologic properties of HA to specifically target CD44-expressing solid tumor tissues and initially improved median progression-free survival and clinical outcomes of colorectal and small cell lung cancer patients in two different trials $(247,248)$. However, another HA-irinotecan trial demonstrated statistically significant improvement in progressionfree survival of metastatic colorectal cancer patients in Phase II trials but could not reproduce these results in Phase III studies (255), indicating that further trials are still needed. Finally, the aforementioned A6/SPL-108 peptide showed a promise in several ovarian cancer trials. Continuous daily consumption was well tolerated without any dose-limiting toxicity and time to clinical disease progression was significantly increased in the EOC patient population $(251,252)$. However, A6/SPL-108 had minimal activity in patients with persistent or recurrent disease (253), indicating a need for further optimization or, potentially, incorporating dual inhibition of CD44 and its relevant interaction partners, such as STAT3.

\section{CONCLUSIONS AND FUTURE DIRECTIONS}

Ovarian cancer is one of the leading causes of death due to malignancy among women worldwide. Frequent metastasis due to advanced stage at the time of diagnosis, disease recurrence, and chemoresistance are major hurdles in the clinic and there is an urgent need to identify suitable molecular targets that drive the disease and design specific therapeutic strategies to circumvent these problems. CD44 and STAT3 cooperate at multiple levels in both malignant and the normal cells in the tumor microenvironment, leading to cancer progression and resistance to therapies. In addition, a critical role of CD44/ STAT3 interaction in inducing immunosuppression has been highlighted. These findings taken together suggest that targeting CD44-STAT3 axis effectively can be an advantageous strategy for treating ovarian cancer.

While we did not discuss the recent advances of PARP inhibitors, accumulating clinical data indicate they can have excellent responses in a subset of ovarian patients with BRCA 1, BRCA2 or other homologous recombination alterations (256). However, PARP inhibitor-resistance is common (257) and PARP inhibitor-treatment leads to activation of STAT3 (258), which likely increases the expression of CD44. The possibility of targeting CD44/STAT3 axis to boost the 
TABLE 2 | Clinical studies investigated the efficacy of CD44 targeting.

\begin{tabular}{|c|c|c|c|c|c|c|}
\hline Ref. & Phase & Cancer type & $\begin{array}{l}\text { Target } \\
\text { isoform }\end{array}$ & $\begin{array}{l}\text { Drug name/ } \\
\text { conjugation }\end{array}$ & Outcome & Adverse effects \\
\hline$(245)$ & Phase I & $\begin{array}{l}\text { Head and neck squamous } \\
\text { cell carcinoma }\end{array}$ & CD44v6 & Bivatuzumab & Fatal drug-related adverse event occurred, termination & $\begin{array}{l}\text { Skin-related adverse } \\
\text { events }\end{array}$ \\
\hline$(245)$ & Phase I & Squamous cell carcinoma & CD44v6 & Bivatuzumab & $14 \%$ (2 of 7 ) patients had stable disease & $\begin{array}{l}\text { One drug-related fatality } \\
\text { and various grade skin } \\
\text { reactions }\end{array}$ \\
\hline$(246)$ & Phase I & $\begin{array}{l}\text { Head and neck squamous } \\
\text { cell carcinoma }\end{array}$ & CD44v6 & Bivatuzumab & Fatal drug-related adverse event occurred, termination & $\begin{array}{l}\text { Skin-related adverse } \\
\text { events }\end{array}$ \\
\hline$(247)$ & $\begin{array}{l}\text { Phase } \\
\text { ॥ }\end{array}$ & $\begin{array}{l}\text { 5-FU-resistant metastatic } \\
\text { colorectal cancer }\end{array}$ & CD44 & $\begin{array}{l}\mathrm{HA}- \\
\text { Irinotecan }\end{array}$ & $17 \%$ partial response and 50\% stable disease & Dose-limiting toxicity \\
\hline$(248)$ & $\begin{array}{l}\text { Phase } \\
\text { lla }\end{array}$ & $\begin{array}{l}\text { Extensive-Stage Small Cell } \\
\text { Lung Cancer }\end{array}$ & CD44 & $\begin{array}{l}\mathrm{HA}- \\
\text { Irinotecan }\end{array}$ & No difference in survival outcomes & Not reported \\
\hline$(249)$ & Phase I & $\begin{array}{l}\text { CD44-expressing solid } \\
\text { tumors }\end{array}$ & CD44 & RG7356 & $21 \%$ patients had stable disease & $\begin{array}{l}\text { Fever, headache and } \\
\text { fatigue }\end{array}$ \\
\hline$(250)$ & Phase I & $\begin{array}{l}\text { Relapsed/refractory acute } \\
\text { myeloid leukemia }\end{array}$ & CD44 & RG7356 & $\begin{array}{l}\text { One patient had stable disease; } 2 \text { patients complete response with } \\
\text { incomplete platelet recovery or partial response }\end{array}$ & $\begin{array}{l}\text { Dose-limiting toxicity } \\
\text { and moderate adverse } \\
\text { events }\end{array}$ \\
\hline$(251)$ & Phase I & $\begin{array}{l}\text { Advanced gynecologic } \\
\text { cancer }\end{array}$ & CD44 & A6 & $\begin{array}{l}\text { The safety outcome in this Phase1b gynecologic } \\
\text { cancer trial was excellent and showed no } \\
\text { specific toxicity profile }\end{array}$ & $\begin{array}{l}\text { No systemic drug- } \\
\text { related adverse events }\end{array}$ \\
\hline (252) & $\begin{array}{l}\text { Phase } \\
\text { II }\end{array}$ & $\begin{array}{l}\text { epithelial ovarian, fallopian } \\
\text { tube, or primary peritoneal } \\
\text { cancer }\end{array}$ & CD44 & A6 & $36 \%(4 / 11)$ of patients had disease stable & $\begin{array}{l}\text { No systemic drug- } \\
\text { related adverse events }\end{array}$ \\
\hline (253) & $\begin{array}{l}\text { Phase } \\
\text { II }\end{array}$ & $\begin{array}{l}\text { Persistent or recurrent } \\
\text { epithelial ovarian, fallopian } \\
\text { tube, or primary } \\
\text { peritoneal carcinoma }\end{array}$ & CD44 & A6 & $\begin{array}{l}6.5 \% \text { were progression free for at least } 6 \text { months } 18.5 \%(2 / 27) \text {; with } \\
\text { CD } 44+\text { expression }\end{array}$ & $\begin{array}{l}\text { One fatal drug-related } \\
\text { event }\end{array}$ \\
\hline (254) & Phase I & $\begin{array}{l}\text { Advanced ovarian epithelial } \\
\text { cancer }\end{array}$ & CD44 & SPL-108 & $\begin{array}{l}\text { Phase I: health volunteers no systemic adverse events; phase lb: } \\
\text { showed self-limited, mild or moderate adverse events with several } \\
\text { subjects showing stable disease }\end{array}$ & Not reported \\
\hline
\end{tabular}

antitumor efficacies of PARP inhibitors and overcome PARP inhibitor resistance may lead to better treatment for ovarian cancer patients.

\section{AUTHOR CONTRIBUTIONS}

HY and LR-R conceived and supervised the manuscript writing. AM created the figures, found and summarized relevant literature findings for each chapter and wrote the final manuscript. P-CL created the tables and summarized relevant literature findings for most of the manuscript parts. QZ prepared and summarized relevant findings for CD44 and STAT3 in Ovarian Cancer Metabolism section of the manuscript under the guidance of Y-JL. CZ prepared and summarized relevant findings for CD44 and STAT3 in Regulatory T Cells and CD44

\section{REFERENCES}

1. Siegel RL, Miller KD, Jemal A. Cancer statistics, 2020. CA Cancer J Clin (2020) 70(1):7-30. doi: 10.3322/caac.21590

2. Matulonis UA, Sood AK, Fallowfield L, Howitt BE, Sehouli J, Karlan BY. Ovarian cancer. Nat Rev Dis Primers (2016) 2(1):16061. doi: 10.1038/nrdp.2016.61

3. Torre LA, Trabert B, DeSantis CE, Miller KD, Samimi G, Runowicz CD, et al. Ovarian cancer statistics, 2018. CA Cancer J Clin (2018) 68(4):284-96. doi: $10.3322 /$ caac. 21456

4. International Agency for Research on Cancer. Global Cancer Observatory (GLOBOCAN) (2020). Available at: https://gco.iarc.fr/today/home (Accessed on 3/6/2020). and STAT3 in Regulatory B Cells sections of the manuscript. All authors contributed to the article and approved the submitted version.

\section{FUNDING}

This work is supported by the Markel-Friedman Accelerator Fund.

\section{ACKNOWLEDGMENTS}

The authors thank Nicola Welch, PhD CMPP, for editorial assistance and critical review of the manuscript.

5. O'Toole S, O'Leary J. "Ovarian cancer chemoresistance". In: M Schwab, editor. Encyclopedia of Cancer. Berlin: Springer (2011). doi: 10.1007/978-3642-16483-5_6930

6. Pokhriyal R, Hariprasad R, Kumar L, Hariprasad G. Chemotherapy Resistance in Advanced Ovarian Cancer Patients. Biomark Cancer (2019) 11:1179299x19860815. doi: 10.1177/1179299X19860815

7. Sapiezynski J, Taratula O, Rodriguez-Rodriguez L, Minko T. Precision targeted therapy of ovarian cancer. J Control Release (2016) 243:250-68. doi: 10.1016/j.jconrel.2016.10.014

8. Hatina J, Boesch M, Sopper S, Kripnerova M, Wolf D, Reimer D, et al. Ovarian Cancer Stem Cell Heterogeneity. Adv Exp Med Biol (2019) 1139:201-21. doi: 10.1007/978-3-030-14366-4_12 
9. Agarwal R, Kaye SB. Ovarian cancer: strategies for overcoming resistance to chemotherapy. Nat Rev Cancer (2003) 3(7):502-16. doi: 10.1038/ $\operatorname{nrc1123}$

10. Yan Y, Zuo X, Wei D. Concise Review: Emerging Role of CD44 in Cancer Stem Cells: A Promising Biomarker and Therapeutic Target. Stem Cells Transl Med (2015) 4(9):1033-43. doi: 10.5966/sctm.2015-0048

11. Zöller M. CD44: can a cancer-initiating cell profit from an abundantly expressed molecule? Nat Rev Cancer (2011) 11(4):254-67. doi: 10.1038/ nrc3023

12. Chen C, Zhao S, Karnad A, Freeman JW. The biology and role of CD44 in cancer progression: therapeutic implications. J Hematol Oncol (2018) 11 (1):64. doi: 10.1186/s13045-018-0605-5

13. Ponta H, Sherman L, Herrlich PA. CD44: From adhesion molecules to signalling regulators. Nat Rev Mol Cell Biol (2003) 4(1):33-45. doi: 10.1038/ nrm1004

14. Lucas MG, Green AM, Telen MJ. Characterization of the serum In(Lu)related antigen: identification of a serum protein related to erythrocyte $\mathrm{p} 80$. Blood (1989) 73(2):596-600. doi: 10.1182/blood.V73.2.596.bloodjournal 732596

15. Goldstein LA, Zhou DF, Picker LJ, Minty CN, Bargatze RF, Ding JF, et al. A human lymphocyte homing receptor, the hermes antigen, is related to cartilage proteoglycan core and link proteins. Cell (1989) 56(6):1063-72. doi: 10.1016/0092-8674(89)90639-9

16. Stamenkovic I, Amiot M, Pesando JM, Seed B. A lymphocyte molecule implicated in lymph node homing is a member of the cartilage link protein family. Cell (1989) 56(6):1057-62. doi: 10.1016/0092-8674(89) 90638-7

17. Basakran NS. CD44 as a potential diagnostic tumor marker. Saudi Med J (2015) 36(3):273-9. doi: 10.15537/smj.2015.3.9622

18. Senbanjo LT, Chellaiah MA. CD44: A Multifunctional Cell Surface Adhesion Receptor Is a Regulator of Progression and Metastasis of Cancer Cells. Front Cell Dev Biol (2017) 5:18. doi: 10.3389/fcell.2017.00018

19. Naor D, Nedvetzki S, Golan I, Melnik L, Faitelson Y. CD44 in cancer. Crit Rev Clin Lab Sci (2002) 39(6):527-79. doi: 10.1080/10408360290795574

20. Bennett KL, Jackson DG, Simon JC, Tanczos E, Peach R, Modrell B, et al. CD44 isoforms containing exon V3 are responsible for the presentation of heparin-binding growth factor. J Cell Biol (1995) 128(4):687-98. doi: 10.1083/jcb.128.4.687

21. Greenfield B, Wang WC, Marquardt H, Piepkorn M, Wolff EA, Aruffo A, et al. Characterization of the heparan sulfate and chondroitin sulfate assembly sites in CD44. J Biol Chem (1999) 274(4):2511-7. doi: 10.1074/ jbc.274.4.2511

22. Naor D, Wallach-Dayan SB, Zahalka MA, Sionov RV. Involvement of CD44, a molecule with a thousand faces, in cancer dissemination. Semin Cancer Biol (2008) 18(4):260-7. doi: 10.1016/j.semcancer.2008.03.015

23. Thapa R, Wilson GD. The Importance of CD44 as a Stem Cell Biomarker and Therapeutic Target in Cancer. Stem Cells Int (2016) 2016:2087204. doi: $10.1155 / 2016 / 2087204$

24. Hu J, Li G, Zhang P, Zhuang X, Hu GW. A CD44v+ subpopulation of breast cancer stem-like cells with enhanced lung metastasis capacity. Cell Death Dis (2017) 8(3):e2679-9. doi: 10.1038/cddis.2017.72

25. Brown RL, Reinke LM, Damerow MS, Perez D, Chodosh LA, Yang J, et al. CD44 splice isoform switching in human and mouse epithelium is essential for epithelial-mesenchymal transition and breast cancer progression. J Clin Invest (2011) 121(3):1064-74. doi: 10.1172/JCI44540

26. Yae T, Tsuchihashi K, Ishimoto T, Motohara T, Yoshikawa M, Yoshida GJ, et al. Alternative splicing of CD44 mRNA by ESRP1 enhances lung colonization of metastatic cancer cell. Nat Commun (2012) 3:883. doi: $10.1038 /$ ncomms 1892

27. Todaro M, Gaggianesi M, Catalano V, Benfante A, Lovino F, Biffoni M, et al. CD44v6 is a marker of constitutive and reprogrammed cancer stem cells driving colon cancer metastasis. Cell Stem Cell (2014) 14(3):342-56. doi: 10.1016/j.stem.2014.01.009

28. Jiang H, Zhao W, Shao W. Prognostic value of CD44 and CD44v6 expression in patients with non-small cell lung cancer: meta-analysis. Tumour Biol (2014) 35(8):7383-9. doi: 10.1007/s13277-014-2150-3

29. Mayr L, Pirker C, Lötsch D, Van Schoonhoven S, Windhager R, Englinger B, et al. CD44 drives aggressiveness and chemoresistance of a metastatic human osteosarcoma xenograft model. Oncotarget (2017) 8(69):114095108. doi: 10.18632 /oncotarget. 23125

30. Li Z, Chen K, Jiang P, Zhang X, Li X, Li Z. CD44v/CD44s expression patterns are associated with the survival of pancreatic carcinoma patients. Diagn Pathol (2014) 9:79. doi: 10.1186/1746-1596-9-79

31. Wielenga VJ, Heider KH, Offerhaus GJ, Adolf GR, van den Berg FM, Ponta H, et al. Expression of CD44 variant proteins in human colorectal cancer is related to tumor progression. Cancer Res (1993) 53(20):4754-6.

32. Kobayashi K, Matsumoto H, Matsuyama H, Fujii N, Inoue R, Yamamoto Y, et al. Clinical significance of $\mathrm{CD} 44$ variant 9 expression as a prognostic indicator in bladder cancer. Oncol Rep (2016) 36(5):2852-60. doi: 10.3892/ or.2016.5061

33. Lau WM, Teng E, Chong HS, Lopez KA, Tay AY, Salto-Tellez M, et al. CD44v8-10 is a cancer-specific marker for gastric cancer stem cells. Cancer Res (2014) 74(9):2630-41. doi: 10.1158/0008-5472.CAN-13-2309

34. Wang SJ, Wreesmann VB, Bourguignon LY. Association of CD44 V3containing isoforms with tumor cell growth, migration, matrix metalloproteinase expression, and lymph node metastasis in head and neck cancer. Head Neck (2007) 29(6):550-8. doi: 10.1002/hed.20544

35. Legras S, Günthert U, Stauder R, Curt F, Oliferenko S, Kluin-Nelemans HC, et al. A strong expression of CD44-6v correlates with shorter survival of patients with acute myeloid leukemia. Blood (1998) 91(9):3401-13. doi: 10.1182/blood.V91.9.3401.3401_3401_3413

36. Higashi M, Sugaya Y, Soeta S, Yokota A, Ishii G, Harigaya K. CD44 expression during tumor progression of follicular lymphoma. Oncol Rep (2009) 22(5):1135-40. doi: 10.3892/or_00000546

37. Sacks JD, Barbolina MV. Expression and Function of CD44 in Epithelial Ovarian Carcinoma. Biomolecules (2015) 5(4):3051-66. doi: 10.3390/ biom5043051

38. Saegusa M, Machida D, Hashimura M, Okayasu I. CD44 expression in benign, premalignant, and malignant ovarian neoplasms: relation to tumour development and progression. J Pathol (1999) 189(3):326-37. doi: 10.1002/(SICI) 1096-9896(199911)189:3<326::AID-PATH425>3. $0 . \mathrm{CO} ; 2-6$

39. Kayastha S, Freedman AN, Piver MS, Mukkamalla J, Romero-Guittierez M, Werness BA. Expression of the hyaluronan receptor, CD44S, in epithelial ovarian cancer is an independent predictor of survival. Clin Cancer Res (1999) 5(5):1073-6.

40. Cho EY, Choi Y, Chae SW, Sohn JH, Ahn GH. Immunohistochemical study of the expression of adhesion molecules in ovarian serous neoplasms. Pathol Int (2006) 56(2):62-70. doi: 10.1111/j.1440-1827.2006.01925.x

41. Uhl-Steidl M, Müller-Holzner E, Zeimet AG, Adolf GR, Daxenbichler G, Marth C, et al. Prognostic value of CD44 splice variant expression in ovarian cancer. Oncology (1995) 52(5):400-6. doi: 10.1159/000227497

42. Afify AM, Ferguson AW, Davila RM, Werness BA. Expression of CD44S and $\mathrm{CD} 44 \mathrm{v} 5$ is more common in stage III than in stage I serous ovarian carcinomas. Appl Immunohistochem Mol Morphol (2001) 9(4):309-14. doi: 10.1097/00129039-200112000-00004

43. Lin J, Ding D. The prognostic role of the cancer stem cell marker CD44 in ovarian cancer: a meta-analysis. Cancer Cell Int (2017) 17:8. doi: 10.1186/ s12935-016-0376-4

44. Gao Y, Foster R, Yang X, Feng Y, Shen JK, Mankin HJ, et al. Up-regulation of CD44 in the development of metastasis, recurrence and drug resistance of ovarian cancer. Oncotarget (2015) 6(11):9313-26. doi: 10.18632/ oncotarget. 3220

45. Chen H, Hao J, Wang L, Li Y. Coexpression of invasive markers (uPA, CD44) and multiple drug-resistance proteins (MDR1, MRP2) is correlated with epithelial ovarian cancer progression. Br J Cancer (2009) 101(3):43240. doi: 10.1038/sj.bjc. 6605185

46. Biddle A, Gammon L, Fazil B, Mackenzie IC. CD44 staining of cancer stemlike cells is influenced by down-regulation of CD44 variant isoforms and upregulation of the standard CD44 isoform in the population of cells that have undergone epithelial-to-mesenchymal transition. PLoS One (2013) 8(2): e57314. doi: 10.1371/journal.pone.0057314

47. Zhou J, Du Y, Lu Y, Luan B, Xu C, Yu Y, et al. CD44 Expression Predicts Prognosis of Ovarian Cancer Patients Through Promoting EpithelialMesenchymal Transition (EMT) by Regulating Snail, ZEB1, and Caveolin1. Front Oncol (2019) 9:802. doi: 10.3389/fonc.2019.00802 
48. Foster R, Buckanovich RJ, Rueda BR. Ovarian cancer stem cells: working towards the root of stemness. Cancer Lett (2013) 338(1):147-57. doi: 10.1016/j.canlet.2012.10.023

49. Deng J, Wang L, Chen H, Hao J, Ni J, Chang L, et al. Targeting epithelialmesenchymal transition and cancer stem cells for chemoresistant ovarian cancer. Oncotarget (2016) 7(34):55771-88. doi: 10.18632/oncotarget.9908

50. Klemba A, Purzycka-Olewiecka JK, Wcisło G, Czarnecka AM, Lewicki S, Lesyng B, et al. Surface markers of cancer stem-like cells of ovarian cancer and their clinical relevance. Contemp Oncol (Pozn) (2018) 22(1a):48-55. doi: 10.5114/wo.2018.73885

51. Zhang S, Balch C, Chan MW, Lai HC, Matei D, Schilder JM, et al. Identification and characterization of ovarian cancer-initiating cells from primary human tumors. Cancer Res (2008) 68(11):4311-20. doi: 10.1158/ 0008-5472.CAN-08-0364

52. Bapat SA, Mali AM, Koppikar CB, Kurrey NK. Stem and progenitor-like cells contribute to the aggressive behavior of human epithelial ovarian cancer. Cancer Res (2005) 65(8):3025-9. doi: 10.1158/0008-5472.CAN-043931

53. Alvero AB, Chen R, Fu HH, Montagna M, Schwartz PE, Rutherford T, et al. Molecular phenotyping of human ovarian cancer stem cells unravels the mechanisms for repair and chemoresistance. Cell Cycle (2009) 8(1):158-66. doi: $10.4161 /$ cc.8.1.7533

54. Shi MF, Jiao J, Lu WG, Ye F, Ma D, Dong QG, et al. Identification of cancer stem cell-like cells from human epithelial ovarian carcinoma cell line. Cell Mol Life Sci (2010) 67(22):3915-25. doi: 10.1007/s00018-010-0420-9

55. Mor G, Yin G, Chefetz I, Yang Y, Alvero A. Ovarian cancer stem cells and inflammation. Cancer Biol Ther (2011) 11(8):708-13. doi: 10.4161/ cbt.11.8.14967

56. Hu Z, Gao J, Zhang D, Liu Q, Yan L, Gao L, et al. High expression of Lewis y antigen and CD44 is correlated with resistance to chemotherapy in epithelial ovarian cancers. PLoS One (2013) 8(2):e57250. doi: 10.1371/ journal.pone.0057250

57. Zhu LC, Gao J, Hu ZH, Schwab CL, Zhuang HY, Tan MZ, et al. Membranous expressions of Lewis y and CAM-DR-related markers are independent factors of chemotherapy resistance and poor prognosis in epithelial ovarian cancer. Am J Cancer Res (2015) 5(2):830-43.

58. Meng E, Long B, Sullivan P, McClellan S, Finan MA, Reed E, et al. CD44 +/CD24- ovarian cancer cells demonstrate cancer stem cell properties and correlate to survival. Clin Exp Metastasis (2012) 29(8):939-48. doi: 10.1007/ s10585-012-9482-4

59. Bhattacharya R, Mitra T, Ray Chaudhuri S, Roy SS. Mesenchymal splice isoform of CD44 (CD44s) promotes EMT/invasion and imparts stem-like properties to ovarian cancer cells. J Cell Biochem (2018) 119(4):3373-83. doi: $10.1002 /$ jcb. 26504

60. Cheng W, Liu T, Wan X, Gao Y, Wang H. MicroRNA-199a targets CD44 to suppress the tumorigenicity and multidrug resistance of ovarian cancer-initiating cells. FEBS J (2012) 279(11):2047-59. doi: 10.1111/j.1742-4658.2012.08589.x

61. Levy DE, Darnell JEJr. Stats: transcriptional control and biological impact. Nat Rev Mol Cell Biol (2002) 3(9):651-62. doi: 10.1038/nrm909

62. Yu H, Kortylewski M, Pardoll D. Crosstalk between cancer and immune cells: role of STAT3 in the tumour microenvironment. Nat Rev Immunol (2007) 7(1):41-51. doi: 10.1038/nri1995

63. Yu H, Pardoll D, Jove R. STATs in cancer inflammation and immunity: a leading role for STAT3. Nat Rev Cancer (2009) 9(11):798-809. doi: 10.1038/ $\operatorname{nrc} 2734$

64. Wu CJ, Sundararajan V, Sheu BC, Huang RY, Wei LH. Activation of STAT3 and STAT5 Signaling in Epithelial Ovarian CancerProgression: Mechanism and Therapeutic Opportunity. Cancers (Basel)(2019) 12(1):24. doi: 10.3390/ cancers 12010024

65. Liang R, Chen X, Chen L, Wan F, Chen K, Sun Y, et al. STAT3 signaling in ovarian cancer: a potential therapeutic target. J Cancer (2020) 11(4):837-48. doi: $10.7150 /$ jca. 35011

66. Silver DL, Naora H, Liu J, Cheng W, Montell DJ. Activated signal transducer and activator of transcription (STAT) 3: localization in focal adhesions and function in ovarian cancer cell motility. Cancer Res (2004) 64(10):3550-8. doi: 10.1158/0008-5472.CAN-03-3959

67. Saini U, Naidu S, ElNaggar AC, Bid HK, Wallbillich JJ, Bixel K, et al. Elevated STAT3 expression in ovarian cancer ascites promotes invasion and metastasis: a potential therapeutic target. Oncogene (2017) 36(2):168-81. doi: 10.1038/onc.2016.197

68. Jia ZH, Jia Y, Guo FJ, Chen J, Zhang XW, Cui MH. Phosphorylation of STAT3 at Tyr705 regulates MMP-9 production in epithelial ovarian cancer. PLoS One (2017) 12(8):e0183622. doi: 10.1371/journal.pone.0183622

69. Seo JM, Park S, Kim JH. Leukotriene B4 receptor-2 promotes invasiveness and metastasis of ovarian cancer cells through signal transducer and activator of transcription 3 (STAT3)-dependent up-regulation of matrix metalloproteinase 2. J Biol Chem (2012) 287(17):13840-9. doi: 10.1074/ jbc.M111.317131

70. Kessenbrock K, Plaks V, Werb Z. Matrix metalloproteinases: regulators of the tumor microenvironment. Cell (2010) 141(1):52-67. doi: 10.1016/ j.cell.2010.03.015

71. Ji T, Gong D, Han Z, Wei X, Yan Y, Ye F, et al. Abrogation of constitutive Stat3 activity circumvents cisplatin resistant ovarian cancer. Cancer Lett (2013) 341(2):231-9. doi: 10.1016/j.canlet.2013.08.022

72. Duan Z, Foster R, Bell DA, Mahoney J, Wolak K, Vaidya A, et al. Signal transducers and activators of transcription 3 pathway activation in drugresistant ovarian cancer. Clin Cancer Res (2006) 12(17):5055-63. doi: 10.1158/1078-0432.CCR-06-0861

73. Yue P, Zhang X, Paladino D, Sengupta B, Ahmad S, Holloway RW, et al. Hyperactive EGF receptor, Jaks and Stat3 signaling promote enhanced colony-forming ability, motility and migration of cisplatin-resistant ovarian cancer cells. Oncogene (2012) 31(18):2309-22. doi: 10.1038/ onc.2011.409

74. Han Z, Feng J, Hong Z, Chen L, Li W, Liao S, et al. Silencing of the STAT3 signaling pathway reverses the inherent and induced chemoresistance of human ovarian cancer cells. Biochem Biophys Res Commun (2013) 435 (2):188-94. doi: 10.1016/j.bbrc.2013.04.087

75. Marotta LL, et al. The JAK2/STAT3 signaling pathway is required for growth of $\mathrm{CD} 44^{+} \mathrm{CD} 24^{-}$stem cell-like breast cancer cells in human tumors. J Clin Invest (2011) 121(7):2723-35. doi: 10.1172/JCI44745

76. Wang X, Wang G, Zhao Y, Liu X, Ding Q, Shi J, et al. STAT3 mediates resistance of CD44(+)CD24(-/low) breast cancer stem cells to tamoxifen in vitro. J BioMed Res (2012) 26(5):325-35. doi: 10.7555/JBR.26.20110050

77. Wu CT, Huang YC, Chen WC, Chen MF. Effect of Tumor Burden on Tumor Aggressiveness and Immune Modulationin Prostate Cancer: Association with IL-6 Signaling. Cancers(Basel) (2019) 11(7):992. doi: 10.3390/ cancers 11070992

78. Lin $\mathrm{CH}$, Chiang MC, Chen YJ. STAT3 mediates resistance to anoikis and promotes invasiveness of nasopharyngeal cancer cells. Int J Mol Med (2017) 40(5):1549-56. doi: 10.3892/ijmm.2017.3151

79. Li L, Hao X, Qin J, Tang W, He F, Smith A, et al. Antibody against CD44s inhibits pancreatic tumor initiation and postradiation recurrence in mice. Gastroenterology (2014) 146(4):1108-18. doi: 10.1053/j.gastro.2013. 12.035

80. So JY, Smolarek AK, Salerno DM, Maehr H, Uskokovic M, Liu F, et al. Targeting CD44-STAT3 signaling by Gemini vitamin D analog leads to inhibition of invasion in basal-like breast cancer. PLoS One (2013) 8(1): e54020. doi: 10.1371/journal.pone.0054020

81. Chung SS, Aroh C, Vadgama JV. Constitutive activation of STAT3 signaling regulates hTERT and promotes stem cell-like traits in human breast cancer cells. PLoS One (2013) 8(12):e83971. doi: 10.1371/journal.pone.0083971

82. Chang SH, Yeh YH, Lee JL, Hsu YJ, Kuo CT, Chen WJ. Transforming growth factor- $\beta$-mediated CD44/STAT3 signaling contributes to the development of atrial fibrosis and fibrillation. Basic Res Cardiol (2017) 112 (5):58. doi: 10.1007/s00395-017-0647-9

83. Anand V, Khandelwal M, Appunni S, Gupta N, Seth A, Singh P, et al. CD44 splice variant $(\mathrm{CD} 44 \mathrm{v} 3)$ promotes progression of urothelial carcinoma of bladder through Akt/ERK/STAT3 pathways: novel therapeutic approach. J Cancer Res Clin Oncol (2019) 145(11):2649-61. doi: 10.1007/s00432-01903024-9

84. Heinrich PC, Behrmann I, Haan S, Hermanns HM, Müller-Newen G, Schaper F. Principles of interleukin (IL)-6-type cytokine signalling and its regulation. Biochem J (2003) 374(Pt 1):1-20. doi: 10.1042/bj20030407

85. Zong CS, Chan J, Levy DE, Horvath C, Sadowski HB, Wang LH. Mechanism of STAT3 activation by insulin-like growth factor I receptor. J Biol Chem (2000) 275(20):15099-105. doi: 10.1074/jbc.M000089200 
86. Dhar D, Antonucci L, Nakagawa H, Kim JY, Glitzner E, Caruso S, et al. Liver Cancer Initiation Requires p53 Inhibition by CD44-Enhanced Growth Factor Signaling. Cancer Cell (2018) 33(6):1061-77.e6. doi: 10.1016/ j.ccell.2018.05.003

87. Xu YY, Guo M, Yang LQ, Zhou F, Yu C, Wang A, et al. Regulation of CD44v6 expression in gastric carcinoma by the IL-6/STAT3 signaling pathway and its clinical significance. Oncotarget (2017) 8(28):45848-61. doi: 10.18632/oncotarget.17435

88. Kim S, Kil WH, Lee J, Oh SJ, Han J, Jeon M, et al. Zerumbone suppresses EGF-induced CD44 expression through the inhibition of STAT3 in breast cancer cells. Oncol Rep (2014) 32(6):2666-72. doi: 10.3892/or.2014.3514

89. Bourguignon LY, Peyrollier K, Xia W, Gilad E. Hyaluronan-CD44 interaction activates stem cell marker Nanog, Stat-3-mediated MDR1 gene expression, and ankyrin-regulated multidrug efflux in breast and ovarian tumor cells. J Biol Chem (2008) 283(25):17635-51. doi: 10.1074/ jbc.M800109200

90. Su YJ, Lai HM, Chang YW, Chen GY, Lee JL. Direct reprogramming of stem cell properties in colon cancer cells by CD44. EMBO J (2011) 30(15):318699. doi: $10.1038 / \mathrm{emboj} .2011 .211$

91. Qin J, Yang B, Xu BQ, Smithc A, Xu L, Yuan JL, et al. Concurrent CD44s and STAT3 expression in human clear cell renal cellular carcinoma and its impact on survival. Int J Clin Exp Pathol (2014) 7(6):3235-44.

92. Pereira C, Ferreira D, Mendes N, Granja PL, Almeida GM, Oliveira C. Expression of CD44v6-Containing Isoforms Influences CisplatinResponse in Gastric Cancer Cells. Cancers (Basel) (2020) 12(4):858. doi: 10.3390/ cancers 12040858

93. Lee JL, Wang MJ, Chen JY. Acetylation and activation of STAT3 mediated by nuclear translocation of CD44. J Cell Biol (2009) 185(6):949-57. doi: $10.1083 /$ jcb. 200812060

94. Bourguignon LY, Earle C, Wong G, Spevak CC, Krueger K. Stem cell marker (Nanog) and Stat-3 signaling promote MicroRNA-21 expression and chemoresistance in hyaluronan/CD44-activated head and neck squamous cell carcinoma cells. Oncogene (2012) 31(2):149-60. doi: 10.1038/ onc.2011.222

95. Ravindranath AK, Kaur S, Wernyj RP, Kumaran MN, Miletti-Gonzalez KE, Chan $\mathrm{R}$, et al. CD44 promotes multi-drug resistance by protecting $\mathrm{P}$ glycoprotein from FBXO21-mediated ubiquitination. Oncotarget (2015) 6 (28):26308-21. doi: 10.18632/oncotarget.4763

96. Miletti-González KE, Chen S, Muthukumaran N, Saglimbeni GN, Wu X, Yang J, et al. The CD44 receptor interacts with P-glycoprotein to promote cell migration and invasion in cancer. Cancer Res (2005) 65(15):6660-7. doi: 10.1158/0008-5472.CAN-04-3478

97. Zhang X, Liu P, Zhang B, Wang A, Yang M. Role of STAT3 decoy oligodeoxynucleotides on cell invasion and chemosensitivity in human epithelial ovarian cancer cells. Cancer Genet Cytogenet (2010) 197(1):4653. doi: 10.1016/j.cancergencyto.2009.10.004

98. Fang Z, Chen W, Yuan Z, Liu X, Jiang H. LncRNA-MALAT1 contributes to the cisplatin-resistance of lung cancer by upregulating MRP1 and MDR1 via STAT3 activation. BioMed Pharmacother (2018) 101:536-42. doi: 10.1016/ j.biopha.2018.02.130

99. Wang Z, Wang C, Zuo D, Zhang T, Yin F, Zhou Z, et al. Attenuation of STAT3 Phosphorylation Promotes Apoptosis and Chemosensitivity in Human Osteosarcoma Induced by Raddeanin A. Int J Biol Sci (2019) 15 (3):668-79. doi: 10.7150/ijbs.30168

100. Zhang X, Xiao W, Wang L, Tian Z, Zhang J. Deactivation of signal transducer and activator of transcription 3 reverses chemotherapeutics resistance of leukemia cells via down-regulating P-gp. PLoS One (2011) 6 (6):e20965. doi: 10.1371/journal.pone.0020965

101. Alderton GK. The tumour microenvironment drives metastasis. Nat Rev Cancer (2016) 16(4):199-9. doi: 10.1038/nrc.2016.31

102. Baghban R, Roshangar L, Jahanban-Esfahlan R, Seidi K, Ebrahimi-Kalan A, Jaymand $\mathrm{M}$, et al. Tumor microenvironment complexity and therapeutic implications at a glance. Cell Commun Signal (2020) 18(1):59. doi: 10.1186/ s12964-020-0530-4

103. Joyce JA. Therapeutic targeting of the tumor microenvironment. Cancer Cell (2005) 7(6):513-20. doi: 10.1016/j.ccr.2005.05.024
104. De Palma M, Biziato D, Petrova TV. Microenvironmental regulation of tumour angiogenesis. Nat Rev Cancer (2017) 17(8):457-74. doi: 10.1038/ nrc.2017.51

105. Potente M, Gerhardt H, Carmeliet P. Basic and therapeutic aspects of angiogenesis. Cell (2011) 146(6):873-87. doi: 10.1016/j.cell.2011.08.039

106. Trochon V, Mabilat C, Bertrand P, Legrand Y, Smadja-Joffe F, Soria C, et al. Evidence of involvement of CD44 in endothelial cell proliferation, migration and angiogenesis in vitro. Int J Cancer (1996) 66(5):664-8. doi: 10.1002/ (SICI) 1097-0215(19960529)66:5<664::AID-IJC14>3.0.CO;2-4

107. Savani RC, Cao G, Pooler PM, Zaman A, Zhou Z, DeLisser HM. Differential involvement of the hyaluronan (HA) receptors CD44 and receptor for HAmediated motility in endothelial cell function and angiogenesis. J Biol Chem (2001) 276(39):36770-8. doi: 10.1074/jbc.M102273200

108. Murphy JF, Lennon F, Steele C, Kelleher D, Fitzgerald D, Long AC. Engagement of CD44 modulates cyclooxygenase induction, VEGF generation, and proliferation in human vascular endothelial cells. FASEB $J$ (2005) 19(3):446-8. doi: 10.1096/fj.03-1376fje

109. Rahmanian M, Heldin P. Testicular hyaluronidase induces tubular structures of endothelial cells grown in three-dimensional collagen gel through a CD44mediated mechanism. Int J Cancer (2002) 97(5):601-7. doi: 10.1002/ ijc.10087

110. Griffioen AW, Coenen MJ, Damen CA, Hellwig SM, van Weering DH, Vooys W, et al. CD44 is involved in tumor angiogenesis; an activation antigen on human endothelial cells. Blood (1997) 90(3):1150-9. doi: 10.1182/ blood.V90.3.1150.1150_1150_1159

111. Ohizumi I, Harada N, Taniguchi K, Tsutsumi Y, Nakagawa S, Kaiho S, et al. Association of CD44 with OTS-8 in tumor vascular endothelial cells. Biochim Biophys Acta (2000) 1497(2):197-203. doi: 10.1016/S0167-4889(00)00063-X

112. Forster-Horváth C, Mészáros L, Rásó E, Döme B, Ladányi A, Morini M, et al. Expression of CD44v3 protein in human endothelial cells in vitro and in tumoral microvessels in vivo. Microvasc Res (2004) 68(2):110-8. doi: 10.1016/j.mvr.2004.05.001

113. Yildiz E, Gokce G, Kilicarslan H, Ayan S, Goze OF, Gultekin EY. Prognostic value of the expression of Ki-67, CD44 and vascular endothelial growth factor, and microvessel invasion, in renal cell carcinoma. BJU Int (2004) 93 (7):1087-93. doi: 10.1111/j.1464-410X.2004.04786.x

114. Cao G, Savani RC, Fehrenbach M, Lyons C, Zhang L, Coukos G, et al. Involvement of endothelial CD44 during in vivo angiogenesis. Am J Pathol (2006) 169(1):325-36. doi: 10.2353/ajpath.2006.060206

115. Chen Z, Han ZC. STAT3: a critical transcription activator in angiogenesis. Med Res Rev (2008) 28(2):185-200. doi: 10.1002/med.20101

116. Niu G, Wright KL, Huang M, Song L, Haura E, Turkson J, et al. Constitutive Stat3 activity up-regulates VEGF expression and tumor angiogenesis. Oncogene (2002) 21(13):2000-8. doi: 10.1038/sj.onc. 1205260

117. Xu Q, Briggs J, Park S, Niu G, Kortylewski M, Zhang S, et al. Targeting Stat3 blocks both HIF-1 and VEGF expression induced by multiple oncogenic growth signaling pathways. Oncogene (2005) 24(36):5552-60. doi: 10.1038/ sj.onc. 1208719

118. Zhao M, Gao FH, Wang JY, Liu F, Yuan HH, Zhang WY, et al. JAK2/STAT3 signaling pathway activation mediates tumor angiogenesis by upregulation of VEGF and bFGF in non-small-cell lung cancer. Lung Cancer (2011) 73 (3):366-74. doi: 10.1016/j.lungcan.2011.01.002

119. Wei D, Le X, Zheng L, Wang L, Frey JA, Gao AC, et al. Stat3 activation regulates the expression of vascular endothelial growth factor and human pancreatic cancer angiogenesis and metastasis. Oncogene (2003) 22(3):31929. doi: 10.1038/sj.onc.1206122

120. Chen Y, Liu Y, Wang Y, Li W, Wang X, Liu X, et al. Quantification of STAT3 and VEGF expression for molecular diagnosis of lymph node metastasis in breast cancer. Med (Baltimore) (2017) 96(45):e8488. doi: 10.1097/ MD.0000000000008488

121. Kujawski M, Kortylewski M, Lee H, Herrmann A, Kay H, Yu H. Stat3 mediates myeloid cell-dependent tumor angiogenesis in mice. J Clin Invest (2008) 118(10):3367-77. doi: 10.1172/JCI35213

122. Chen H, Ye D, Xie X, Chen B, Lu W. VEGF, VEGFRs expressions and activated STATs in ovarian epithelial carcinoma. Gynecol Oncol (2004) 94 (3):630-5. doi: 10.1016/j.ygyno.2004.05.056 
123. Lu W, Chen H, Yel F, Wang F, Xie X. VEGF induces phosphorylation of STAT3 through binding VEGFR2 in ovarian carcinoma cells in vitro. Eur J Gynaecol Oncol (2006) 27(4):363-9.

124. Wang YZ, Cao ML, Liu YL, He YQ, Yang CX, Gao F. CD44 mediates oligosaccharides of hyaluronan-induced proliferation, tube formation and signal transduction in endothelial cells. Exp Biol Med (Maywood) (2011) 236 (1):84-90. doi: 10.1258/ebm.2010.010206

125. Rundhaug JE. Matrix metalloproteinases and angiogenesis. J Cell Mol Med (2005) 9(2):267-85. doi: 10.1111/j.1582-4934.2005.tb00355.x

126. Mi Z, Bhattacharya SD, Kim VM, Guo H, Talbot LJ, Kuo PC. Osteopontin promotes CCL5-mesenchymal stromal cell-mediated breast cancer metastasis. Carcinogenesis (2011) 32(4):477-87. doi: 10.1093/carcin/bgr009

127. Zhang R, Pan X, Huang Z, Weber GF, Zhang G. Osteopontin enhances the expression and activity of MMP-2 via the SDF-1/CXCR4 axis in hepatocellular carcinoma cell lines. PLoS One (2011) 6(8):e23831. doi: 10.1371/journal.pone.0023831

128. Miletti-González KE, Murphy K, Kumaran MN, Ravindranath AK, Wernyj RP, Kaur S, et al. Identification of function for CD44 intracytoplasmic domain (CD44-ICD): modulation of matrix metalloproteinase 9 (MMP-9) transcription via novel promoter response element. J Biol Chem (2012) 287 (23):18995-9007. doi: 10.1074/jbc.M111.318774

129. Ma L, Chang P. CD44v6 engages in colorectal cancer progression. Cell Death Dis (2019) 10(1):30. doi: 10.1038/s41419-018-1265-7

130. Wang L, Duan W, Kang L, Mao J, Yu X, Fan S, et al. Smoothened activates breast cancer stem-like cell and promotes tumorigenesis and metastasis of breast cancer. BioMed Pharmacother (2014) 68(8):1099-104. doi: 10.1016/ j.biopha.2014.09.012

131. Yu Q, Stamenkovic I. Localization of matrix metalloproteinase 9 to the cell surface provides a mechanism for CD44-mediated tumor invasion. Genes $\operatorname{Dev}$ (1999) 13(1):35-48. doi: 10.1101/gad.13.1.35

132. Yu Q, Stamenkovic I. Cell surface-localized matrix metalloproteinase-9 proteolyticallyactivates TGF-beta and promotes tumor invasion and angiogenesis. GenesDev (2000)14(2):163-76. doi: 10.1101/gad.14.2.163

133. Desai B, Rogers MJ, Chellaiah MA. Mechanisms of osteopontin and CD44 as metastatic principles in prostate cancer cells. Mol Cancer (2007) 6:18. doi: 10.1186/1476-4598-6-18

134. Xie TX, Wei D, Liu M, Gao AC, Ali-Osman F, Sawaya R, et al. Stat3 activation regulates the expression of matrix metalloproteinase- 2 and tumor invasion and metastasis. Oncogene (2004) 23(20):3550-60. doi: 10.1038/ sj.onc. 1207383

135. Dechow TN, Pedranzini L, Leitch A, Leslie K, Gerald WL, Linkov I, et al. Requirement of matrix metalloproteinase-9 for the transformation of human mammary epithelial cells by Stat3-C. Proc Natl Acad Sci U S A (2004) 101 (29):10602-7. doi: 10.1073/pnas.0404100101

136. Niu G, Wright KL, Ma Y, Wright GM, Huang M, Irby R, et al. Role of Stat3 in regulating p53 expression and function. Mol Cell Biol (2005) 25(17):7432-40. doi: 10.1128/MCB.25.17.7432-7440.2005

137. Turkson J, Bowman T, Garcia R, Caldenhoven E, De Groot RP, Jove R. Stat3 activation by Src induces specific gene regulation and is required for cell transformation. Mol Cell Biol (1998) 18(5):2545-52. doi: 10.1128/ MCB.18.5.2545

138. Garcia R, Bowman TL, Niu G, Yu H, Minton S, Muro-Cacho CA, et al. Constitutive activation of Stat 3 by the Src and JAK tyrosine kinases participates in growth regulation of human breast carcinoma cells. Oncogene (2001) 20(20):2499-513. doi: 10.1038/sj.onc.1204349

139. Bromberg JF, Horvath CM, Besser D, Lathem WW, Darnell JE Jr. Stat3 activation is required for cellular transformation by v-src. Mol Cell Biol (1998) 18(5):2553-8. doi: 10.1128/MCB.18.5.2553

140. Yu CL, Meyer DJ, Campbell GS, Larner AC, Carter-Su C, Schwartz J, et al. Enhanced DNA-binding activity of a Stat3-related protein in cells transformed by the Src oncoprotein. Science (1995) 269(5220):81-3. doi: 10.1126/science.7541555

141. Schuringa JJ, Timmer H, Luttickhuizen D, Vellenga E, Kruijer W. c-Jun and c-Fos cooperate with STAT3 in IL-6-induced transactivation of the IL-6 respone element (IRE). Cytokine (2001) 14(2):78-87. doi: 10.1006/ cyto.2001.0856

142. Trachana SP, Pilalis E, Gavalas NG, Tzannis K, Papadodima O, Liontos M, et al. The Development of an Angiogenic Protein "Signature" in Ovarian
Cancer Ascites as a Tool for Biologic and Prognostic Profiling. PLoS One (2016) 11(6):e0156403. doi: 10.1371/journal.pone.0156403

143. Kalluri R. The biology and function of fibroblasts in cancer. Nat Rev Cancer (2016) 16(9):582-98. doi: 10.1038/nrc.2016.73

144. Monteran L, Erez N. The Dark Side of Fibroblasts: Cancer-Associated Fibroblasts as Mediators of Immunosuppression in the Tumor Microenvironment. Front Immunol (2019) 10:1835. doi: 10.3389/ fimmu.2019.01835

145. Dasari S, Fang Y, Mitra AK. Cancer Associated Fibroblasts: Naughty Neighbors That Drive OvarianCancer Progression. Cancers (Basel) (2018) 10(11):406. doi: 10.3390/cancers10110406

146. Wang W, Kryczek I, Dostál L, Lin H, Tan L, Zhao L, et al. Effector T Cells Abrogate Stroma-Mediated Chemoresistance in Ovarian Cancer. Cell (2016) 165(5):1092-105. doi: 10.1016/j.cell.2016.04.009

147. Rodríguez-Rodríguez L, Sancho-Torres I, Mesonero C, Gibbon DG, Shih WJ, Zotalis G. The CD44 receptor is a molecular predictor of survival in ovarian cancer. Med Oncol (2003) 20(3):255-63. doi: 10.1385/MO:20:3:255

148. Yeung TL, Leung CS, Wong KK, Samimi G, Thompson MS, Liu J, et al. TGF$\beta$ modulates ovarian cancer invasion by upregulating CAF-derived versican in the tumor microenvironment. Cancer Res (2013) 73(16):5016-28. doi: 10.1158/0008-5472.CAN-13-0023

149. Wang L, Zhang F, Cui JY, Chen L, Chen YT, Liu BW. CAFs enhance paclitaxel resistance by inducing EMT through the IL-6/JAK2/STAT3 pathway. Oncol Rep (2018) 39(5):2081-90. doi: 10.3892/or.2018.6311

150. Yan H, Guo BY, Zhang S. Cancer-associated fibroblasts attenuate Cisplatininduced apoptosis in ovarian cancer cells by promoting STAT3 signaling. Biochem Biophys Res Commun (2016) 470(4):947-54. doi: 10.1016/ j.bbrc.2016.01.131

151. Kinugasa Y, Matsui T, Takakura N. CD44 expressed on cancer-associated fibroblasts is a functional molecule supporting the stemness and drug resistance of malignant cancer cells in the tumor microenvironment. Stem Cells (2014) 32(1):145-56. doi: 10.1002/stem.1556

152. Liu Y, Yu C, Wu Y, Sun X, Su Q, You C, et al. CD44(+) fibroblasts increases breast cancer cell survival and drug resistance via IGF2BP3CD44-IGF2 signalling. J Cell Mol Med (2017) 21(9):1979-88. doi: $10.1111 / \mathrm{jcmm} .13118$

153. Yang X, Lin Y, Shi Y, Li B, Liu W, Yin W, et al. FAP Promotes Immunosuppression by Cancer-Associated Fibroblasts in the Tumor Microenvironment via STAT3-CCL2 Signaling. Cancer Res (2016) 76 (14):4124-35. doi: 10.1158/0008-5472.CAN-15-2973

154. Wang Y, Jing Y, Ding L, Zhang X, Song Y, Chen S, et al. Epiregulin reprograms cancer-associated fibroblasts and facilitates oral squamous cell carcinoma invasion via JAK2-STAT3 pathway. J Exp Clin Cancer Res (2019) 38(1):274. doi: 10.1186/s13046-019-1277-x

155. Hendrayani SF, Al-Khalaf HH, Aboussekhra A. The cytokine IL-6 reactivates breast stromal fibroblasts through transcription factor STAT3-dependent up-regulation of the RNA-binding protein AUF1. J Biol Chem (2014) 289 (45):30962-76. doi: 10.1074/jbc.M114.594044

156. Gabrilovich DI, Nagaraj S. Myeloid-derived suppressor cells as regulators of the immune system. Nat Rev Immunol (2009) 9(3):162-74. doi: 10.1038/ nri2506

157. Kumar V, Patel S, Tcyganov E, Gabrilovich DI. The Nature of MyeloidDerived Suppressor Cells in the Tumor Microenvironment. Trends Immunol (2016) 37(3):208-20. doi: 10.1016/j.it.2016.01.004

158. Fleming V, Hu X, Weber R, Nagibin V, Groth C, Altevogt P, et al. Targeting Myeloid-Derived Suppressor Cells to Bypass Tumor-Induced Immunosuppression. Front Immunol (2018) 9:398. doi: 10.3389/ fimmu.2018.00398

159. Baert T, Vankerckhoven A, Riva M, Van Hoylandt A, Thirion G, Holger G, et al. Myeloid Derived Suppressor Cells: Key Drivers of Immunosuppression in Ovarian Cancer. Front Immunol (2019) 10:1273. doi: 10.3389/ fimmu. 2019.01273

160. Cui TX, Kryczek I, Zhao L, Zhao E, Kuick R, Roh MH, et al. Myeloid-derived suppressor cells enhance stemness of cancer cells by inducing microRNA101 and suppressing the corepressor CtBP2. Immunity (2013) 39(3):611-21. doi: 10.1016/j.immuni.2013.08.025

161. Okła K, Czerwonka A, Wawruszak A, Bobiński M, Bilska R, Tarkowski R, et al. Clinical Relevance and Immunosuppressive Pattern of Circulating and 
Infiltrating Subsets of Myeloid-Derived Suppressor Cells (MDSCs) in Epithelial Ovarian Cancer. Front Immunol (2019) 10:691. doi: 10.3389/ fimmu.2019.00691

162. Liu L, Wang X, Li X, Wu X, Tang M, Wang X. Upregulation of IGF1 by tumor-associated macrophages promotes the proliferation and migration of epithelial ovarian cancer cells. Oncol Rep (2018) 39(2):818-26. doi: 10.3892/ or.2017.6148

163. Horikawa N, Abiko K, Matsumura N, Hamanishi J, Baba T, Yamaguchi K, et al. Expression of Vascular Endothelial Growth Factor in Ovarian Cancer Inhibits Tumor Immunity through the Accumulation of Myeloid-Derived Suppressor Cells. Clin Cancer Res (2017) 23(2):587-99. doi: 10.1158/10780432.CCR-16-0387

164. Huang B, Lei Z, Zhao J, Gong W, Liu J, Chen Z, et al. CCL2/CCR2 pathway mediates recruitment of myeloid suppressor cells to cancers. Cancer Lett (2007) 252(1):86-92. doi: 10.1016/j.canlet.2006.12.012

165. Sica A, Saccani A, Bottazzi B, Bernasconi S, Allavena P, Gaetano A, et al. Defective expression of the monocyte chemotactic protein-1 receptor CCR2 in macrophages associated with human ovarian carcinoma. J Immunol (2000) 164(2):733-8. doi: 10.4049/jimmunol.164.2.733

166. Chikamatsu K, Takahashi G, Sakakura K, Ferrone S, Masuyama K. Immunoregulatory properties of CD44+ cancer stem-like cells in squamous cell carcinoma of the head and neck. Head Neck (2011) 33 (2):208-15. doi: 10.1002/hed.21420

167. Höchst B, Schildberg FA, Sauerborn P, Gäbel YA, Gevensleben H, Goltz $\mathrm{D}$, et al. Activated human hepatic stellate cells induce myeloid derived suppressor cells from peripheral blood monocytes in a CD44dependent fashion. J Hepatol (2013) 59(3):528-35. doi: 10.1016/ j.jhep.2013.04.033

168. Nefedova Y, Nagaraj S, Rosenbauer A, Muro-Cacho C, Sebti SM, Gabrilovich DI. Regulation of dendritic cell differentiation and antitumor immune response in cancer by pharmacologic-selective inhibition of the janusactivated kinase 2/signal transducers and activators of transcription 3 pathway. Cancer Res (2005) 65(20):9525-35. doi: 10.1158/0008-5472.CAN05-0529

169. Nefedova Y, Huang M, Kusmartsev S, Bhattacharya R, Cheng P, Salup R, et al. Hyperactivation of STAT3 is involved in abnormal differentiation of dendritic cells in cancer. J Immunol (2004) 172(1):464-74. doi: 10.4049/ jimmunol.172.1.464

170. Kortylewski M, Kujawski M, Wang T, Wei S, Zhang S, Pilon-Thomas S, et al. Inhibiting Stat 3 signaling in the hematopoietic system elicits multicomponent antitumor immunity. Nat Med (2005) 11(12):1314-21. doi: $10.1038 / \mathrm{nm} 1325$

171. Panni RZ, Sanford DE, Belt BA, Mitchem JB, Worley LA, Goetz BD, et al. Tumor-induced STAT3 activation in monocytic myeloid-derived suppressor cells enhances stemness and mesenchymal properties in human pancreatic cancer. Cancer Immunol Immunother (2014) 63(5):513-28. doi: 10.1007/ s00262-014-1527-x

172. Wu L, Deng Z, Peng Y, Han L, Liu J, Wang L, et al. Ascites-derived IL-6 and IL-10 synergistically expand CD14(+)HLA-DR(-/low) myeloid-derived suppressor cells in ovarian cancer patients. Oncotarget (2017) 8 (44):76843-56. doi: 10.18632/oncotarget.20164

173. Nowak M, Klink M. The Role of Tumor-Associated Macrophages in the Progression andChemoresistance of Ovarian Cancer. Cells (2020)9(5):1299. doi: 10.3390/cells9051299

174. Pollard JW. Tumour-educated macrophages promote tumour progression and metastasis. Nat Rev Cancer (2004) 4(1):71-8. doi: 10.1038/nrc1256

175. Condeelis J, Pollard JW. Macrophages: obligate partners for tumor cell migration, invasion, and metastasis. Cell (2006) 124(2):263-6. doi: 10.1016/j.cell.2006.01.007

176. Zhou J, Tang Z, Gao S, Li C, Feng Y, Zhou X. Tumor-Associated Macrophages: Recent Insights and Therapies. Front Oncol (2020) 10:188. doi: 10.3389/fonc.2020.00188

177. Mu X, Shi W, Xu Y, Xu C, Zhao T, Geng B, et al. Tumor-derived lactate induces M2 macrophage polarization via the activation of the ERK/STAT3 signaling pathway in breast cancer. Cell Cycle (2018) 17(4):428-38. doi: 10.1080/15384101.2018.1444305

178. Yin Z, Ma T, Lin Y, Lu X, Zhang C, Chen S, et al. IL-6/STAT3 pathway intermediates M1/M2 macrophage polarization during the development of hepatocellular carcinoma. J Cell Biochem (2018) 119(11):9419-32. doi: $10.1002 /$ jcb. 27259

179. Hussain SF, Kong LY, Jordan J, Conrad C, Madden T, Fokt I, et al. A novel small molecule inhibitor of signal transducers and activators of transcription 3 reverses immune tolerance in malignant glioma patients. Cancer Res (2007) 67(20):9630-6. doi: 10.1158/0008-5472.CAN-07-1243

180. Zhang M, He Y, Sun X, Li Q, Wang W, Zhao A, et al. A high M1/M2 ratio of tumor-associated macrophages is associated with extended survival in ovarian cancer patients. J Ovarian Res (2014) 7:19. doi: 10.1186/17572215-7-19

181. Jeannin P, Duluc D, Delneste Y. IL-6 and leukemia-inhibitory factor are involved in the generation of tumor-associated macrophage: regulation by IFN- $\gamma$. Immunotherapy (2011) 3(4 Suppl):23-6. doi: 10.2217/imt.11.30

182. Takaishi K, Komohara Y, Tashiro H, Ohtake H, Nakagawa T, Katabuchi H, et al. Involvement of M2-polarized macrophages in the ascites from advanced epithelial ovarian carcinoma in tumor progression via Stat3 activation. Cancer Sci (2010) 101(10):2128-36. doi: 10.1111/j.13497006.2010.01652.x

183. Yin M, Li X, Tan S, Zhou HJ, Ji W, Bellone S, et al. Tumor-associated macrophages drive spheroid formation during early transcoelomic metastasis of ovarian cancer. J Clin Invest (2016) 126(11):4157-73. doi: $10.1172 / J C I 87252$

184. Ning Y, Cui Y, Li X, Cao X, Chen A, Xu C, et al. Co-culture of ovarian cancer stem-like cells with macrophages induced SKOV3 cells stemness via IL-8/ STAT3 signaling. BioMed Pharmacother (2018) 103:262-71. doi: 10.1016/ j.biopha.2018.04.022

185. Zou W. Regulatory T cells, tumour immunity and immunotherapy. Nat Rev Immunol (2006) 6(4):295-307. doi: 10.1038/nri1806

186. Curiel TJ, Coukos G, Zou L, Alvarez X, Cheng P, Mottram P, et al. Specific recruitment of regulatory $\mathrm{T}$ cells in ovarian carcinoma fosters immune privilege and predicts reduced survival. Nat Med (2004) 10(9):942-9. doi: $10.1038 / \mathrm{nm} 1093$

187. Toker A, Nguyen LT, Stone SC, Yang SYC, Katz SR, Shaw PA, et al. Regulatory T Cells in Ovarian Cancer Are Characterized by a Highly Activated Phenotype Distinct from that in Melanoma. Clin Cancer Res (2018) 24(22):5685-96. doi: 10.1158/1078-0432.CCR-18-0554

188. Ou Y, Cannon MJ, Nakagawa M. Regulatory T Cells in Gynecologic Cancer. MOJ Immunol (2018) 6(2):34-42. doi: 10.15406/moji.2018.06.00189

189. Landskron J, Helland Ø, Torgersen KM, Aandahl EM, Gjertsen BT, Bjørge L, et al. Activated regulatory and memory T-cells accumulate in malignant ascites from ovarian carcinoma patients. Cancer Immunol Immunother (2015) 64(3):337-47. doi: 10.1007/s00262-014-1636-6

190. Wolf D, Wolf AM, Rumpold H, Fiegl H, Zeimet AG, Muller-Holzner E, et al. The expression of the regulatory $\mathrm{T}$ cell-specific forkhead box transcription factor FoxP3 is associated with poor prognosis in ovarian cancer. Clin Cancer Res (2005) 11(23):8326-31. doi: 10.1158/1078-0432.CCR-05-1244

191. Liu T, Soong L, Liu G, König R, Chopra AK. CD44 expression positively correlates with Foxp3 expression and suppressive function of CD4+ Treg cells. Biol Direct (2009) 4:40. doi: 10.1186/1745-6150-4-40

192. Till BG, Press OW. Depletion of Tregs for adoptive T-cell therapy using CD44 and CD137 as selection markers. Immunotherapy (2012) 4(5):483-5. doi: $10.2217 /$ imt.12.33

193. Bollyky PL, Falk BA, Long SA, Preisinger A, Braun KR, Wu RP, et al. CD44 costimulation promotes FoxP3+ regulatory $\mathrm{T}$ cell persistence and function via production of IL-2, IL-10, and TGF-beta. J Immunol (2009) 183(4):223241. doi: 10.4049/jimmunol.0900191

194. Pallandre JR, Brillard E, Créhange G, Radlovic A, Remy-Martin JP, Saas P, et al. Role of STAT3 in CD4+CD25+FOXP3+ regulatory lymphocyte generation: implications in graft-versus-host disease and antitumor immunity. J Immunol (2007) 179(11):7593-604. doi: 10.4049/ jimmunol.179.11.7593

195. Chaudhry A, Rudra D, Treuting P, Samstein RM, Liang Y, Kas A, et al. CD4+ regulatory T cells control TH17 responses in a Stat3-dependent manner. Science (2009) 326(5955):986-91. doi: 10.1126/science.1172702

196. Hossain DM, Panda AK, Manna A, Mohanty S, Bhattacharjee P, Bhattacharyya S, et al. FoxP3 acts as a cotranscription factor with STAT3 in tumor-induced regulatory T cells. Immunity (2013) 39(6):1057-69. doi: 10.1016/j.immuni.2013.11.005 
197. Gupta P, Chen C, Chaluvally-Raghavan P, Pradeep S. B Cells as an ImmuneRegulatory Signature in OvarianCancer. Cancers (Basel) (2019) 11(7):894. doi: 10.3390/cancers 11070894

198. Dong HP, Elstrand MB, Holth A, Silins I, Berner A, Trope CG, et al. NK- and B-cell infiltration correlates with worse outcome in metastatic ovarian carcinoma. Am J Clin Pathol (2006) 125(3):451-8. doi: 10.1309/ 15B66DQMFYYM78CJ

199. Wei X, Jin Y, Tian Y, Zhang H, Wu J, Lu W, et al. Regulatory B cells contribute to the impaired antitumor immunity in ovarian cancer patients. Tumour Biol (2016) 37(5):6581-8. doi: 10.1007/s13277-015-4538-0

200. Yang C, Lee H, Pal S, Jove V, Deng J, Zhang W, et al. B cells promote tumor progression via STAT3 regulated-angiogenesis. PLoS One (2013) 8(5): e64159. doi: 10.1371/journal.pone.0064159

201. Zhang C, Xin H, Zhang W, Yazaki PJ, Zhang Z, Le K, et al. CD5 Binds to Interleukin-6 and Induces a Feed-Forward Loop with the Transcription Factor STAT3 in B Cells to Promote Cancer. Immunity (2016) 44(4):913-23. doi: 10.1016/j.immuni.2016.04.003

202. Yang C, Lee H, Jove V, Deng J, Zhang W, Liu X, et al. Prognostic significance of B-cells and pSTAT3 in patients with ovarian cancer. PLoS One (2013) 8(1): e54029. doi: 10.1371/journal.pone.0054029

203. Högerkorp CM, Bilke S, Breslin T, Ingvarsson S, Borrebaeck CA. CD44stimulated human B cells express transcripts specifically involved in immunomodulation and inflammation as analyzed by DNA microarrays. Blood (2003) 101(6):2307-13. doi: 10.1182/blood-2002-06-1837

204. Pavlova NN, Thompson CB. The Emerging Hallmarks of Cancer Metabolism. Cell Metab (2016) 23(1):27-47. doi: 10.1016/j.cmet.2015.12.006

205. Koppenol WH, Bounds PL, Dang CV. Otto Warburg's contributions to current concepts of cancer metabolism. Nat Rev Cancer (2011) 11(5):325-37. doi: $10.1038 / \mathrm{nrc} 3038$

206. Chakraborty PK, Mustafi SB, Xiong X, Dwivedi SKD, Nesin V, Saha S, et al. MICU1 drives glycolysis and chemoresistance in ovarian cancer. Nat Commun (2017) 8:14634. doi: 10.1038/ncomms14634

207. Tamada M, Nagano O, Tateyama S, Ohmura M, Yae T, Ishimoto T, et al. Modulation of glucose metabolism by CD44 contributes to antioxidant status and drug resistance in cancer cells. Cancer Res (2012) 72(6):143848. doi: 10.1158/0008-5472.CAN-11-3024

208. Li W, Cohen A, Sun Y, Squires J, Braas D, Graeber TG, et al. The Role of CD44 in Glucose Metabolism in Prostatic Small Cell Neuroendocrine Carcinoma. Mol Cancer Res (2016) 14(4):344-53. doi: 10.1158/15417786.MCR-15-0466

209. Ciavardelli D, Rossi C, Barcaroli D, Volpe S, Consalvo A, Zucchelli M, et al. Breast cancer stem cells rely on fermentative glycolysis and are sensitive to 2deoxyglucose treatment. Cell Death Dis (2014) 5(7):e1336. doi: 10.1038/ cddis.2014.285

210. Peng F, Wang JH, Fan WJ, Meng YT, Li MM, Li TT, et al. Glycolysis gatekeeper PDK1 reprograms breast cancer stem cells under hypoxia. Oncogene (2018) 37(8):1062-74. doi: 10.1038/onc.2017.368

211. Nam K, Oh S, Shin I. Ablation of CD44 induces glycolysis-to-oxidative phosphorylation transition via modulation of the c-Src-Akt-LKB1-AMPK $\alpha$ pathway. Biochem J (2016) 473(19):3013-30. doi: 10.1042/BCJ20160613

212. Ryu D, Ryoo IG, Kwak MK. Overexpression of CD44 Standard Isoform Upregulates HIF-1 $\alpha$ Signaling in Hypoxic Breast Cancer Cells. Biomol Ther (Seoul) (2018) 26(5):487-93. doi: 10.4062/biomolther.2018.116

213. Alvero AB, Montagna MK, Sumi NJ, Joo WD, Graham E, Mor G. Multiple blocks in the engagement of oxidative phosphorylation in putative ovarian cancer stem cells: implication for maintenance therapy with glycolysis inhibitors. Oncotarget (2014) 5(18):8703-15. doi: 10.18632/oncotarget.2367

214. Demaria M, Giorgi C, Lebiedzinska M, Esposito G, D'Angeli L, Bartoli A, et al. A STAT3-mediated metabolic switch is involved in tumour transformation and STAT3 addiction. Aging (Albany NY) (2010) 2 (11):823-42. doi: 10.18632/aging.100232

215. Demaria M, Poli V. PKM2, STAT3 and HIF-1 $\alpha$ : The Warburg's vicious circle. Jakstat (2012) 1(3):194-6. doi: 10.4161/jkst.20662

216. Sola-Penna M, Paixão LP, Branco JR, Ochioni AC, Albanese JM, Mundim $\mathrm{DM}$, et al. Serotonin activates glycolysis and mitochondria biogenesis in human breast cancer cells through activation of the Jak1/STAT3/ERK1/2 and adenylate cyclase/PKA, respectively. Br J Cancer (2020) 122(2):194-208. doi: $10.1038 /$ s41416-019-0640-1
217. Santos CR, Schulze A. Lipid metabolism in cancer. FEBS J (2012) 279 (15):2610-23. doi: 10.1111/j.1742-4658.2012.08644.x

218. Röhrig F, Schulze A. The multifaceted roles of fatty acid synthesis in cancer. Nat Rev Cancer (2016) 16(11):732-49. doi: 10.1038/nrc.2016.89

219. Munir R, Lisec J, Swinnen JV, Zaidi N. Lipid metabolism in cancer cells under metabolic stress. Br J Cancer (2019) 120(12):1090-8. doi: 10.1038/ s41416-019-0451-4

220. Ladanyi A, Mukherjee A, Kenny HA, Johnson A, Mitra AK, Sundaresan S, et al. Adipocyte-induced $\mathrm{CD} 36$ expression drives ovarian cancer progression and metastasis. Oncogene (2018) 37(17):2285-301. doi: 10.1038/s41388-017-0093-z

221. Chen RR, Yung MMH, Xuan Y, Zhan S, Leung LL, Liang RR, et al. Targeting of lipid metabolism with a metabolic inhibitor cocktaileradicates peritoneal metastases in ovarian cancer cells. CommunBiol (2019) 2:281. doi: 10.1038/ s42003-019-0508-1

222. Shao H, Mohamed EM, Xu GG, Waters M, Jing K, Ma Y, et al. Carnitine palmitoyltransferase $1 \mathrm{~A}$ functions to repress FoxO transcription factors to allow cell cycle progression in ovarian cancer. Oncotarget (2016) 7(4):383246. doi: 10.18632/oncotarget.6757

223. Zaytseva YY, Rychahou PG, Gulhati P, Elliott VA, Mustain WC, O'Connor $\mathrm{K}$, et al. Inhibition of fatty acid synthase attenuates CD44-associated signaling and reduces metastasis in colorectal cancer. Cancer Res (2012) 72 (6):1504-17. doi: 10.1158/0008-5472.CAN-11-4057

224. Pascual G, Avgustinova A, Mejetta S, Martín M, Castellanos A, Pascual G, et al. Targeting metastasis-initiating cells through the fatty acid receptor CD36. Nature (2017) 541(7635):41-5. doi: 10.1038/nature20791

225. Hershey BJ, Vazzana R, Joppi DL, Havas KM. Lipid Droplets Define a SubPopulation of Breast Cancer StemCells. J Clin Med (2019)9(1):87. doi: $10.3390 / \mathrm{jcm} 9010087$

226. Wang T, Fahrmann JF, Lee H, Li YJ, Tripathi SC, Yue C, et al. JAK/STAT3Regulated Fatty Acid $\beta$-Oxidation Is Critical for Breast Cancer Stem Cell Self-Renewal and Chemoresistance. Cell Metab (2018) 27(1):136-50.e5. doi: 10.1016/j.cmet.2017.11.001

227. Pastò A, Bellio C, Pilotto G, Ciminale V, Silic-Benussi M, Guzzo G, et al. Cancer stem cells from epithelial ovarian cancer patients privilege oxidative phosphorylation, and resist glucose deprivation. Oncotarget (2014) 5 (12):4305-19. doi: 10.18632/oncotarget.2010

228. Sillanpää S, Anttila MA, Voutilainen K, Tammi RH, Tammi MI, Saarikoski $\mathrm{SV}$, et al. CD44 expression indicates favorable prognosis in epithelial ovarian cancer. Clin Cancer Res (2003) 9(14):5318-24.

229. Cannistra SA, Abu-Jawdeh G, Niloff G, Strobel T, Swanson L, Andersen J, et al. CD44 variant expression is a common feature of epithelial ovarian cancer: lack of association with standard prognostic factors. J Clin Oncol (1995) 13(8):1912-21. doi: 10.1200/JCO.1995.13.8.1912

230. Heider KH, Sproll M, Susani S, Patzelt E, Beaumier P, Ostermann E, et al. Characterization of a high-affinity monoclonal antibody specific for CD44v6 as candidate for immunotherapy of squamous cell carcinomas. Cancer Immunol Immunother (1996) 43(4):245-53. doi: 10.1007/ s002620050329

231. Jin L, Hope KJ, Zhai Q, Smadja-Joffe F, Dick JE. Targeting of CD44 eradicates human acute myeloid leukemic stem cells. Nat Med (2006) 12 (10):1167-74. doi: 10.1038/nm1483

232. Zhang S, Wu CC, Fecteau JF, Cui B, Chen L, Zhang L, et al. Targeting chronic lymphocytic leukemia cells with a humanized monoclonal antibody specific for CD44. Proc Natl Acad Sci U S A (2013) 110(15):6127-32. doi: 10.1073/ pnas. 1221841110

233. Luo Y, Prestwich GD. Synthesis and selective cytotoxicity of a hyaluronic acid-antitumor bioconjugate. Bioconjug Chem (1999) 10(5):755-63. doi: $10.1021 / \mathrm{bc} 9900338$

234. Journo-Gershfeld G, Kapp D, Shamay Y, Kopeček J, David A. Hyaluronan oligomers-HPMA copolymer conjugates for targeting paclitaxel to CD44overexpressing ovarian carcinoma. Pharm Res (2012) 29(4):1121-33. doi: 10.1007/s11095-012-0672-1

235. Hibino S, Shibuya M, Engbring JA, Mochizuki M, Nomizu M, Kleinman HK. Identification of an active site on the laminin alpha5 chain globular domain that binds to CD44 and inhibits malignancy. Cancer Res (2004) 64(14):48106. doi: 10.1158/0008-5472.CAN-04-0129

236. Boyd DD, Kim SJ, Wang H, Jones TR, Gallick GE. A urokinase-derived peptide (A6) increases survival of mice bearing orthotopically grown prostate 
cancer and reduces lymph node metastasis. Am J Pathol (2003) 162(2):61926. doi: 10.1016/S0002-9440(10)63855-2

237. Piotrowicz RS, Damaj BB, Hachicha M, Incardona F, Howell SB, Finlayson M. A6 peptide activates CD44 adhesive activity, induces FAK and MEK phosphorylation, and inhibits the migration and metastasis of CD44expressing cells. Mol Cancer Ther (2011) 10(11):2072-82. doi: 10.1158/ 1535-7163.MCT-11-0351

238. Finlayson M. Modulation of CD44 Activity by A6-Peptide. Front Immunol (2015) 6:135. doi: 10.3389/fimmu.2015.00135

239. Chung SS, Vadgama JV. Curcumin and epigallocatechin gallate inhibit the cancer stem cell phenotype via down-regulation of STAT3-NFKB signaling. Anticancer Res (2015) 35(1):39-46.

240. Li X, Wang H, Ding J, Nie S, Wang L, Zhang L, et al. Celastrol strongly inhibits proliferation, migration and cancer stem cell properties through suppression of Pin1 in ovarian cancer cells. Eur J Pharmacol (2019) 842:14656. doi: 10.1016/j.ejphar.2018.10.043

241. Annett S, Moore G, Short A, Marshall A, McCrudden C, Yakkundi A, et al. FKBPL-based peptide, ALM201, targets angiogenesis and cancer stem cells in ovarian cancer. Br J Cancer (2020) 122(3):361-71. doi: 10.1038/s41416019-0649-5

242. Jia L, Zhou J, Zhao H, Jin H, Lv M, Zhao N, et al. Corilagin sensitizes epithelial ovarian cancer to chemotherapy by inhibiting Snail-glycolysis pathways. Oncol Rep (2017) 38(4):2464-70. doi: 10.3892/or.2017.5886

243. Sonbol MB, Ahn DH, Bekaii-Saab T. Therapeutic Targeting Strategies of Cancer Stem Cells inGastrointestinal Malignancies. Biomedicines (2019)7 (1):17. doi: 10.3390/biomedicines7010017

244. Beyreis M, Gaisberger M, Jakab M, Neureiter D, Helm K, Ritter M, et al. The Cancer Stem Cell Inhibitor Napabucasin (BBI608) Shows GeneralCytotoxicity in Biliary Tract Cancer Cells and Reduces Cancer Stem CellCharacteristics. Cancers (Basel) (2019)11(3):276. doi: 10.3390/cancers11030276

245. Tijink BM, Buter J, de Bree R, Giaccone G, Lang MS, Staab A, et al. A phase I dose escalation study with anti-CD44v6 bivatuzumab mertansine in patients with incurable squamous cell carcinoma of the head and neck or esophagus. Clin Cancer Res (2006) 12(20 Pt 1):6064-72. doi: 10.1158/1078-0432.CCR-06-0910

246. Riechelmann H, Sauter A, Golze W, Hanft G, Schroen C, Hoermann K, et al. Phase I trial with the CD44v6-targeting immunoconjugate bivatuzumab mertansine in head and neck squamous cell carcinoma. Oral Oncol (2008) 44 (9):823-9. doi: 10.1016/j.oraloncology.2007.10.009

247. Gibbs P, Clingan PR, Ganju V, Strickland AH, Wong SS, Tebbutt NC, et al. Hyaluronan-Irinotecan improves progression-free survival in 5-fluorouracil refractory patients with metastatic colorectal cancer: a randomized phase II trial. Cancer Chemother Pharmacol (2011) 67(1):153-63. doi: 10.1007/ s00280-010-1303-3

248. Alamgeer M, Neil Watkins D, Banakh I, Kumar B, Gough DJ, Markman B, et al. A phase IIa study of HA-irinotecan, formulation of hyaluronic acid and irinotecan targeting CD44 in extensive-stage small cell lung cancer. Invest New Drugs (2018) 36(2):288-98. doi: 10.1007/s10637-017-0555-8

249. Menke-van der Houven van Oordt CW, Gomez-Roca C, van Herpen C, Coveler AL, Mahalingam D, Verheul HM, et al. First-in-human phase I clinical trial of RG7356, an anti-CD44 humanized antibody, in patients with advanced, CD44-expressing solid tumors. Oncotarget (2016) 7(48):8004658. doi: 10.18632/oncotarget.11098
250. Vey N, Delaunay J, Martinelli G, Fiedler W, Raffoux E, Prebet T, et al. Phase I clinical study of RG7356, an anti-CD44 humanized antibody, in patients with acute myeloid leukemia. Oncotarget (2016) 7(22):32532-42. doi: 10.18632 /oncotarget. 8687

251. Berkenblit A, Matulonis UA, Kroener JF, Dezube BJ, Lam GN, Cuasay LC, et al. A6, a urokinase plasminogen activator (uPA)-derived peptide in patients with advanced gynecologic cancer: a phase I trial. Gynecol Oncol (2005) 99(1):50-7. doi: 10.1016/j.ygyno.2005.05.023

252. Ghamande SA, Silverman MH, Huh W, Behbakht K, Ball G, Cuasay L, et al. A phase 2, randomized, double-blind, placebo-controlled trial of clinical activity and safety of subcutaneous A6 in women with asymptomatic CA125 progression after first-line chemotherapy of epithelial ovarian cancer. Gynecol Oncol (2008) 111(1):89-94. doi: 10.1016/j.ygyno.2009.03.012

253. Gold MA, Brady WE, Lankes HA, Rose PG, Kelley JL, De Geest K, et al. A phase II study of a urokinase-derived peptide (A6) in the treatment of persistent or recurrent epithelial ovarian, fallopian tube, or primary peritoneal carcinoma: a Gynecologic Oncology Group study. Gynecol Oncol (2012) 125(3):635-9. doi: 10.1016/j.ygyno.2012.03.023

254. Girda E, Meritens ABD, Finlayson M, Leiser A, Nelson D, Silverman MH, et al. An open-label phase 1 trial of the safety and efficacy of daily subcutaneous SPL-108 injections when used in combination with paclitaxel in patients with platinum-resistant, CD44+, advanced ovarian epithelial cancer. J Clin Oncol (2018) 36(15_suppl):TPS5608-TPS5608. doi: 10.1200/JCO.2018.36.15_suppl.TPS5608

255. Alchemia Announces Phase III Trial Results for HA-Irinotecan in Metastatic Colorectal Cancer (2014). Available at: https://www.globenewswire.com/ news-release/2014/10/26/1103272/0/en/Alchemia-Announces-Phase-IIITrial-Results-for-HA-Irinotecan-in-Metastatic-Colorectal-Cancer.html.

256. Pilie PG, Tang C, Mills GB, Yap TA. State-of-the-art strategies for targeting the DNA damage response in cancer. Nat Rev Clin Oncol (2019) 16(2):81104. doi: 10.1038/s41571-018-0114-z

257. Noordermeer SM, van Attikum H. PARP Inhibitor Resistance: A Tug-ofWar in BRCA-Mutated Cells. Trends Cell Biol (2019) 29(10):820-34. doi: 10.1016/j.tcb.2019.07.008

258. Ding L, Chen X, Xu X, Qian Y, Liang G, Yao F, et al. PARP1 Suppresses the Transcription of PD-L1 by Poly(ADP-Ribosyl)ating STAT3. Cancer Immunol Res (2019) 7(1):136-49. doi: 10.1158/2326-6066.CIR-18-0071

Conflict of Interest: The authors declare that the research was conducted in the absence of any commercial or financial relationships that could be construed as a potential conflict of interest.

The reviewer AS declared a shared affiliation, with no collaboration, with the authors to the handling editor at the time of review.

Copyright (c) 2020 Martincuks, Li, Zhao, Zhang, Li, Yu and Rodriguez-Rodriguez. This is an open-access article distributed under the terms of the Creative Commons Attribution License (CC BY). The use, distribution or reproduction in other forums is permitted, provided the original author(s) and the copyright owner(s) are credited and that the original publication in this journal is cited, in accordance with accepted academic practice. No use, distribution or reproduction is permitted which does not comply with these terms. 